\title{
Strategies and cognitive reserve to preserve lexical production in aging
}

\author{
Monica Baciu $(\mathbb{D} \cdot$ Sonja Banjac • Elise Roger • \\ Célise Haldin • Marcela Perrone-Bertolotti • \\ Hélène Lœvenbruck • Jean-François Démonet
}

Received: 26 February 2021 / Accepted: 9 April 2021 / Published online: 10 May 2021

(C) The Author(s) 2021

\begin{abstract}
In the absence of any neuropsychiatric condition, older adults may show declining performance in several cognitive processes and among them, in retrieving and producing words, reflected in slower responses and even reduced accuracy compared to younger adults. To overcome this difficulty, healthy older adults implement compensatory strategies, which are the focus of this paper. We provide a review of mainstream findings on deficient mechanisms and possible neurocognitive strategies used by older adults to overcome the deleterious effects of age on lexical production. Moreover, we present findings on genetic and lifestyle factors that might either be protective or risk factors of cognitive impairment in advanced age. We propose that "agingmodulating factors" (AMF) can be modified, offering prevention opportunities against aging effects. Based on our review and this proposition, we introduce an integrative neurocognitive model of mechanisms and compensatory strategies for lexical production in older adults (entitled Lexical Access and Retrieval in Aging, LARA). The main hypothesis defended in LARA is that cognitive aging evolves
\end{abstract}

M. Baciu $(\bowtie) \cdot$ S. Banjac $\cdot$ E. Roger $\cdot$ C. Haldin $\cdot$

M. Perrone-Bertolotti $\cdot$ H. Lœvenbruck

Univ. Grenoble Alpes, CNRS LPNC UMR 5105,

38000 Grenoble, France

e-mail: monica.baciu@univ-grenoble-alpes.fr

J.-F. Démonet

Leenaards Memory Centre, University Hospital of Lausanne,

Lausanne, Switzerland heterogeneously and involves complementary domain-general and domain-specific mechanisms, with substantial inter-individual variability, reflected at behavioral, cognitive, and brain levels. Furthermore, we argue that the ability to compensate for the effect of cognitive aging depends on the amount of reserve specific to each individual which is, in turn, modulated by the AMF. Our conclusion is that a variety of mechanisms and compensatory strategies coexist in the same individual to oppose the effect of age. The role of reserve is pivotal for a successful coping with age-related changes and future research should continue to explore the modulating role of AMF.

Keywords Healthy aging · Lexical · Production · Behavioral $\cdot$ Brain $\cdot$ Reserve factors

\section{Cognitive aging: a focus on lexical production}

As average lifespan increases, the proportion of older people is growing exponentially across the globe. In 2050, people over the age of 65 are expected to make $16.7 \%$ of the world's population ([78]; cited by [87]) and the number of individuals over 60 is projected to triple [8]. This will result in increased demands in terms of health care costs for an aging population, together with increased family, societal, and economic burden. In order to promote healthy aging and prevent neurodegenerative disorders, it is crucial to better understand the adverse processes associated with aging. Cognitive 
aging is not a uniform process, as some cognitive abilities are significantly impaired by age, while others remain unaffected or can even improve. Decreases in the speed of information processing [103], decrements of encoding in episodic memory ([99, 112]; see also [11] for a review), and dysfunctions of working memory $[107,137]$ are generally observed in older adults. Fechner et al. [55] argued that aging affects "the flexibility to form, to switch, and update representations in working memory." Executive functions have an important role, as a "key contributor to age-related declines in a range of cognitive tasks" [66], with a decline in decision-making $[55,74]$, mental flexibility and inhibitory processes [33, 193], and attention [64, 106]. Conversely, over-learned skills and tasks based on individual experience and semantic knowledge may remain unaffected for longer or can even improve with age. Indeed, speech and language skills appear to remain more stable in healthy older adults (see [106], cited by [128]), as well as semantic memory [134], verbal comprehension [179], and vocabulary $[73,138]$.

Despite overall language skills preservation, some linguistic operations can be impaired by age $[68,126$, 144]. For instance, verbal fluency, word retrieval, or confrontation naming can be progressively altered even if older adults may show greater lexical knowledge compared to younger adults $[157,199]$ due to longer accumulated linguistic experience and greater resistance of semantic memory [23]. It is admitted that language comprehension is more resistant to age than language production (see [27, 43, 149, 162, 166, 207]), a discrepancy explained, according to Sheldon et al. [170], by the fact that older adults benefit from the semantic context or the increase of accumulated verbal knowledge through the lifespan [40]. In contrast, language production and specifically lexical generation which involves word retrieval and word production are more frequently impaired by age. Older adults have difficulties in retrieving names $[35,51,88,133]$ and encounter more tipof-the-tongue situations [26, 34, 53, 135,167$]$, i.e., the feeling of knowing the meaning of a word without being able to find and produce the word form immediately. These difficulties are more frequent in adults above 70 years [198] but may also occur earlier [35, 191]. In the present paper, we will specifically focus on lexical production to understand the mechanisms underlying the effect of age on language skills and how some lexical production/cognitive strategies could contribute to healthy aging.
We remind that difficulties encountered by older people to produce words may have several origins. Lexical production involves many coordinated cognitive and linguistic processes which depend on a large brain network including interconnected regions within and between hemispheres and which have intricate time courses [165]. According to dominant neurocognitive models of lexical retrieval reviewed by Friedmann et al. [61], producing a word starts with accessing the conceptual system to retrieve and select the target conceptual representation, which is still not verbally formulated but includes semantic properties, and presumably visual as well as functional representations. Conceptual processing depends on a large set of regions including inferior parietal, middle temporal, fusiform, parahippocampal, dorso-medial, and ventro-medial prefrontal cortices, as well as posterior cingulate, anterior temporal, and anterior part of the inferior frontal gyrus (see also [85, 86, 141]). The activation of lexicosemantic and syntactic representations comes next, recruiting superior middle temporal gyrus, precuneus, inferior frontal, and prefrontal regions [85, 171]. The generated semantic-syntactic representation includes information about the meaning of a word, its semantic properties, and its syntactic function. It activates the phonological representation in the phonological lexicon, which includes metrical information (stress pattern, length) as well as segmental information (consonants, vowels). Phonological encoding has been shown to involve posterior parts of the left superior and middle temporal gyri (e.g., [61]). Some researchers argue for the additional recruitment of the posterior superior temporal gyrus and the temporo-parietal junction, but this remains debated $[61,71]$. According to the set of models reviewed by Friedmann et al. [61], the output of the phonological encoding is transferred to the phonological buffer, which stores phonological representation until the word is fully uttered and which composes metrically and morphologically complex words from their morphemes. The phonological output buffer has itself been associated with an area within the Sylvian fissure at the parietal-temporal boundary called Spt [80]. As synthesized in Friedmann et al. [61], phonetic encoding is the stage during which the phonemic string is prepared for articulation and sent to the motor system. Although this is still a matter of debates, research on speech motor control has suggested that phonetic encoding (sometimes also called articulatory planning, e.g., [71]) includes two phases, motor planning and motor 
programming, that may dissociate in developmental or acquired speech disorders $[102,188,196]$. The regions involved in phonetic encoding include the inferior frontal, ventral premotor and motor cortices, supplementary motor area, and the anterior part of the insula, the thalamus, and the cerebellum [71, 85]. Overall, lexical production involves a vast network of interconnected nodes, linked with the semantic system for word meaning representations, with phonological and orthographic systems for word sound and spelling representations, with the motor system for articulatory representations, and with cognitive control systems, for monitoring (see $[41,61,111,115])$.

Given the large number of operations that are needed for an adequate lexical production, its decline with age may be explained by different mechanisms, either language-specific (LS) or domain-general (DG). An exhaustive presentation of studies on this topic in recent years is beyond the scope of the present paper. We simply provide a synthesis of significant findings published on lexical retrieval and production in normal aging in Table 1. To do that, a literature search was conducted using the PubMed database during November 2020 for a systematic literature review of age-related lexical changes in lexical production, mainly based on a behavioral and neuropsychological approach. Keywords used were "aging/ageing", "lexical", "production", "naming", "tip-of-the-tongue", "language", "healthy" in different combinations (aging OR ageing) AND lexical AND production; (aging OR ageing) AND tip-of-the-tongue; (aging OR ageing) AND naming AND language). Two of the authors first screened the titles and abstracts of the resulting papers to assess their eligibility and then performed full-text scans to determine whether papers met the inclusion criteria. To be included in the review, the studies had to fulfill the following inclusion criteria: published between 2000 and 2020, written in English, the study includes older participants $(60+)$, participants did not suffer from any form of pathology, tasks included one-word production, the study specifically assesses the relationship between lexical production and aging, and employed tasks focus explicitly on language. The studies were left out if they fulfilled one of the following exclusion criteria: tasks included written production, tasks included a sentence or narrative production, and only a neuroimaging approach. Case studies, meta-analysis, and review papers were excluded. Through this process, 46 papers were identified.
Thereafter, we remind the main mechanisms underlying lexical production decline with aging.

\section{Mechanisms involved in lexical production decline with aging}

Regarding language-specific mechanisms, the difficulty to produce a word can first be explained by difficulty to access conceptual and semantic representations [22, 84, 198], even if some authors argue for an additional disruption in semantic processing $[46,195]$. Finding a word can also be imperiled by difficulties to retrieve or activate its phonological representation [2, 45]. Based on the node structure theory (NST; [114]), the transmission deficit hypothesis $[116,187]$ provides a model of age-related activation impairment. According to the NST, linguistic information is stored in interconnected nodes within a large hierarchically organized network with two crucial levels, a phonological system representing the sounds and metrical structure of words and a semantic system representing conceptual and lexical information about words. Language production is assumed to be influenced by the amount and speed of priming transmission across connections between nodes. Priming is a form of excitation that prepares a node for activation, allowing retrieval of the information represented by the node. Under the transmission deficit hypothesis, the strength of connections between nodes would become weaker with age, which would produce priming transmission deficits. Transmission deficits from semantic to phonology can impair activation of phonological nodes, leading to word retrieval failure [1, $25,90,203]$. This hypothesis is supported by neuroimaging data collected by Shafto et al. [168]. They showed that the reduced ability of older adults to find words is related to neural atrophy in regions critical for phonological processes, which decreases the flexibility of the word production network. Overall, these findings suggest that two complementary language-specific mechanisms, one lexico-semantic and another one phonological, can explain age-related difficulties to produce words.

As mentioned above, other non-linguistic or domaingeneral mechanisms can explain lexical production difficulties in older adults, typically a decline in executive functions [76, 81, 204], together with reduced processing speed or not [156]. The processing speed theory attributes cognitive decline to a decrease in information 
(⿸丆口

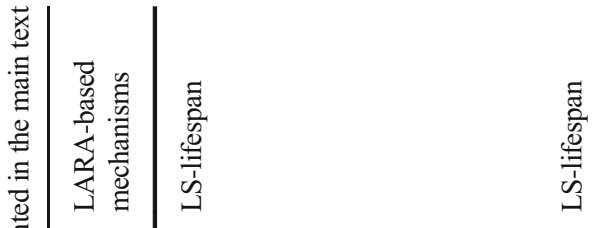

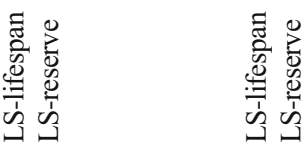

袋

要

造

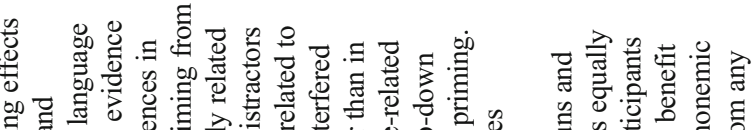

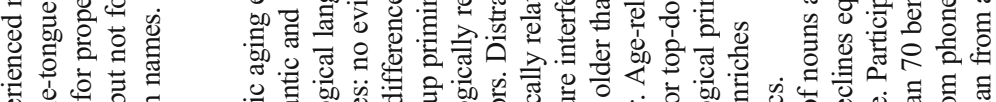

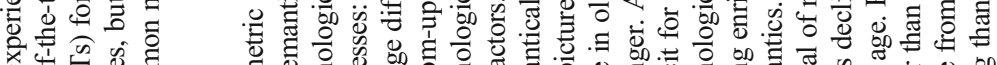

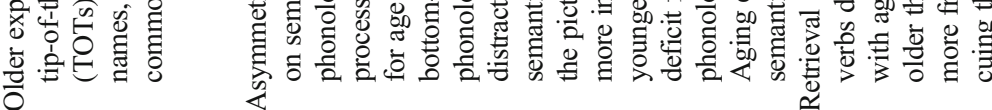

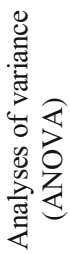

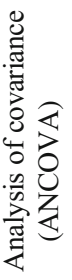

is

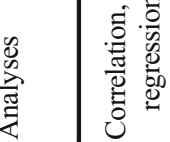

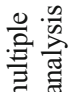

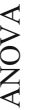

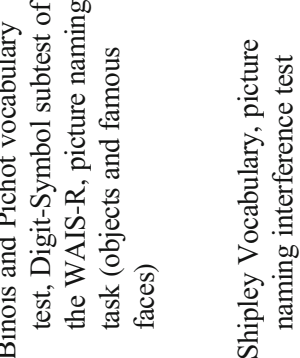

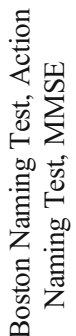

चृ

๙ิ)

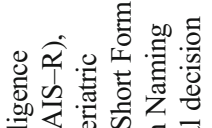

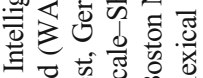

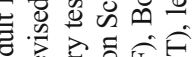

等

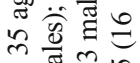

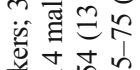

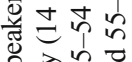

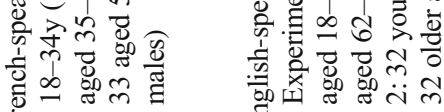

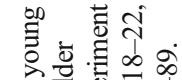

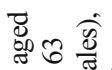

$\checkmark)$

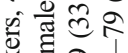

⿶凵

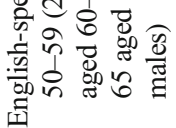

衣总言离总棓

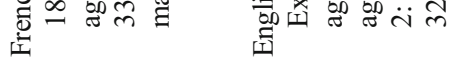

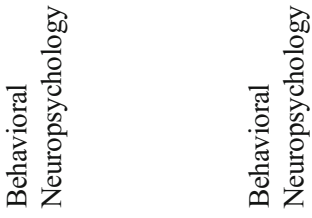

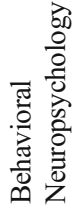

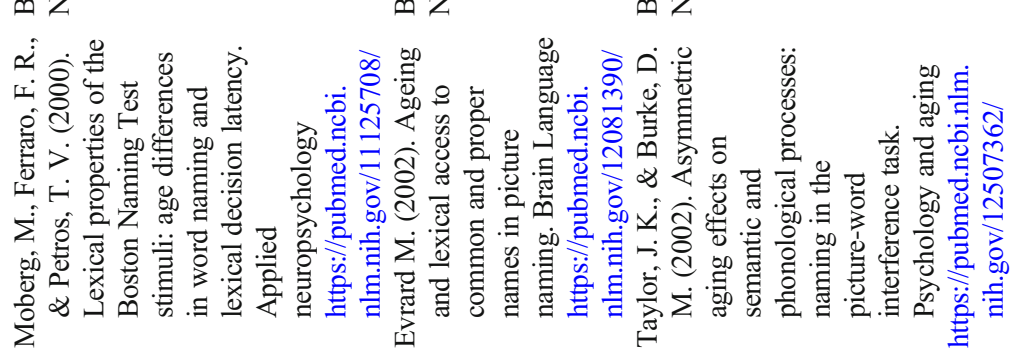

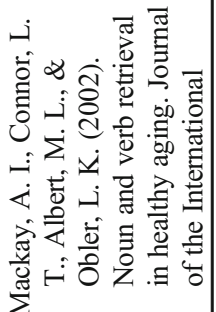




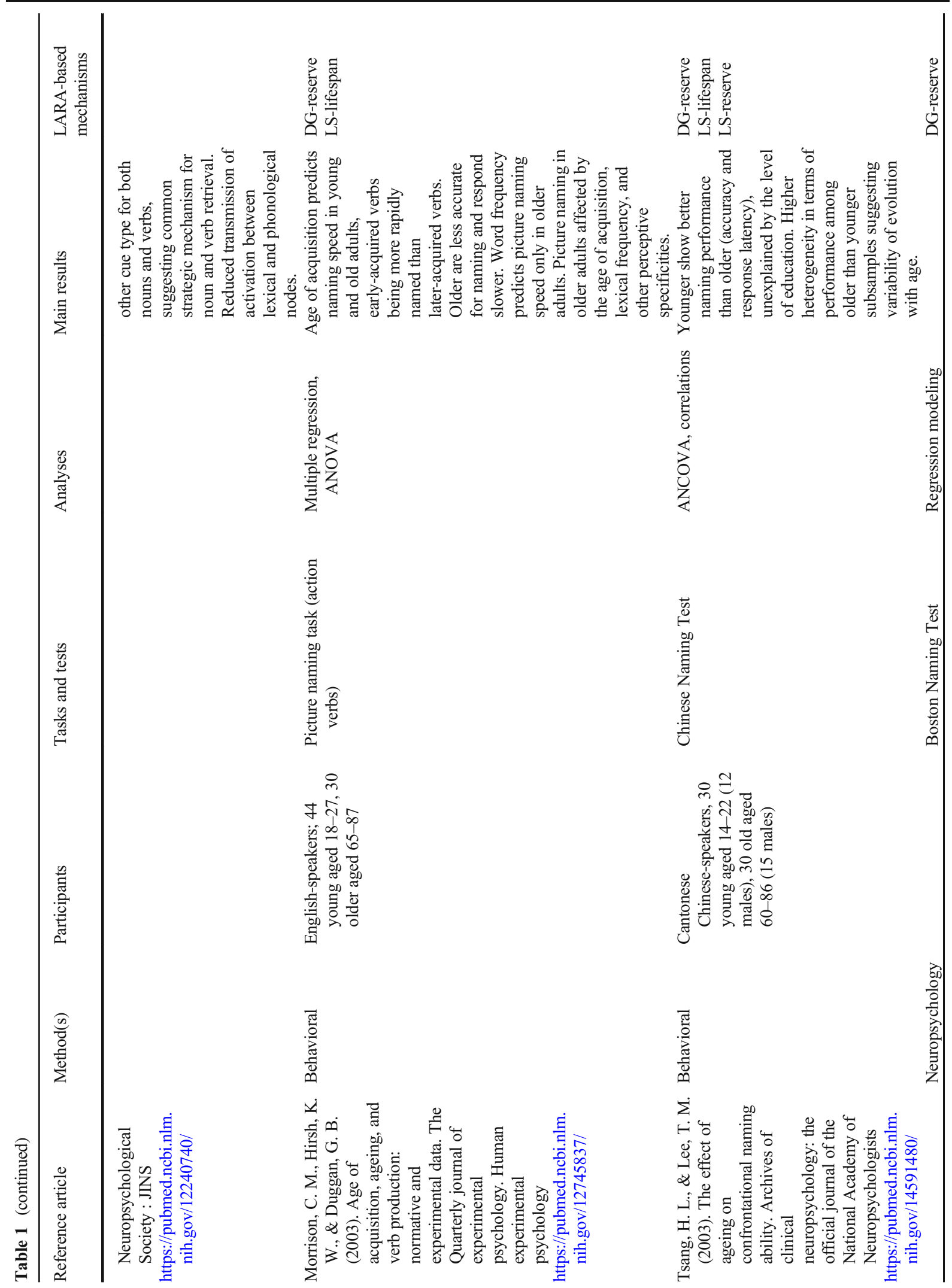




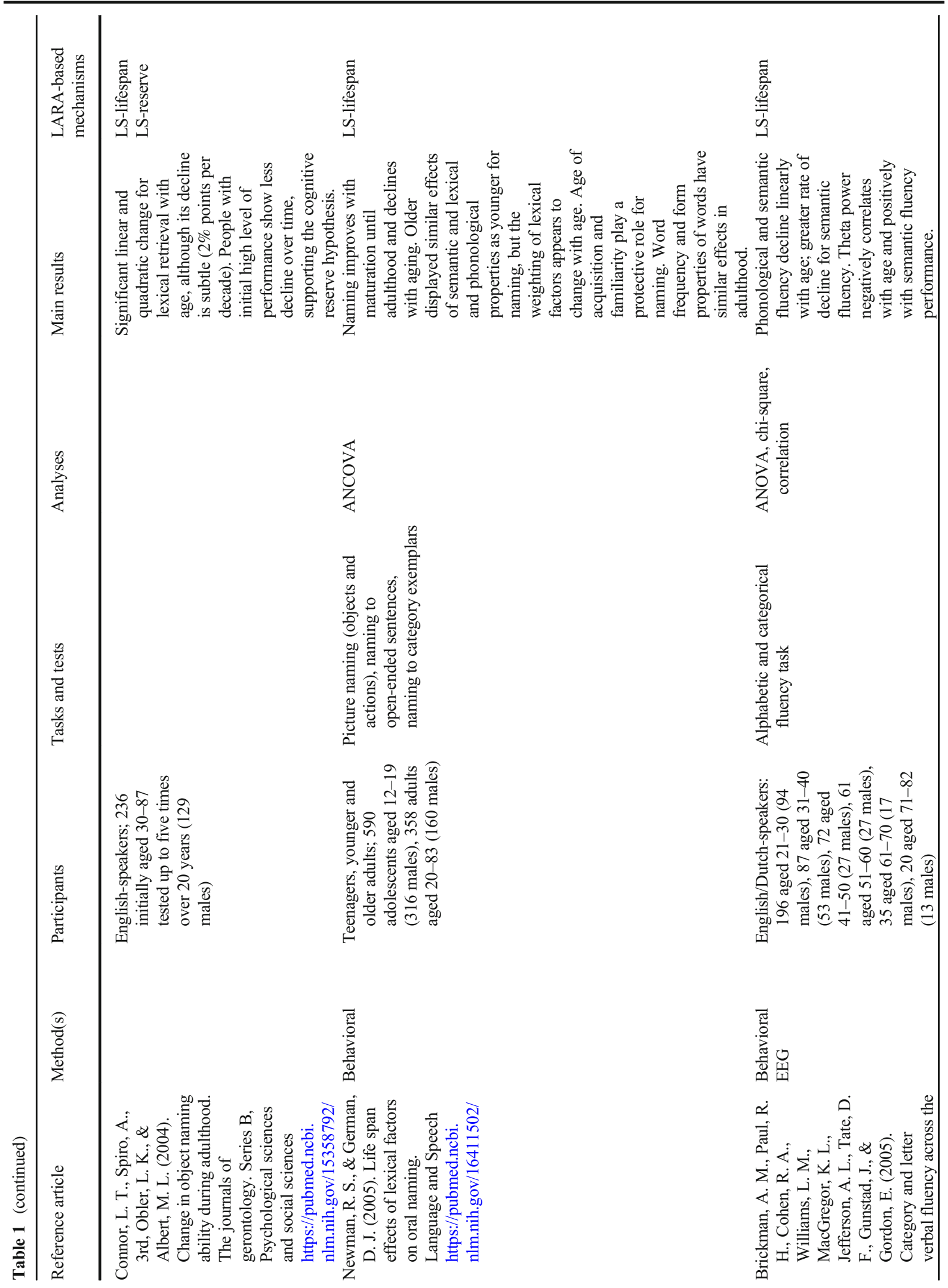




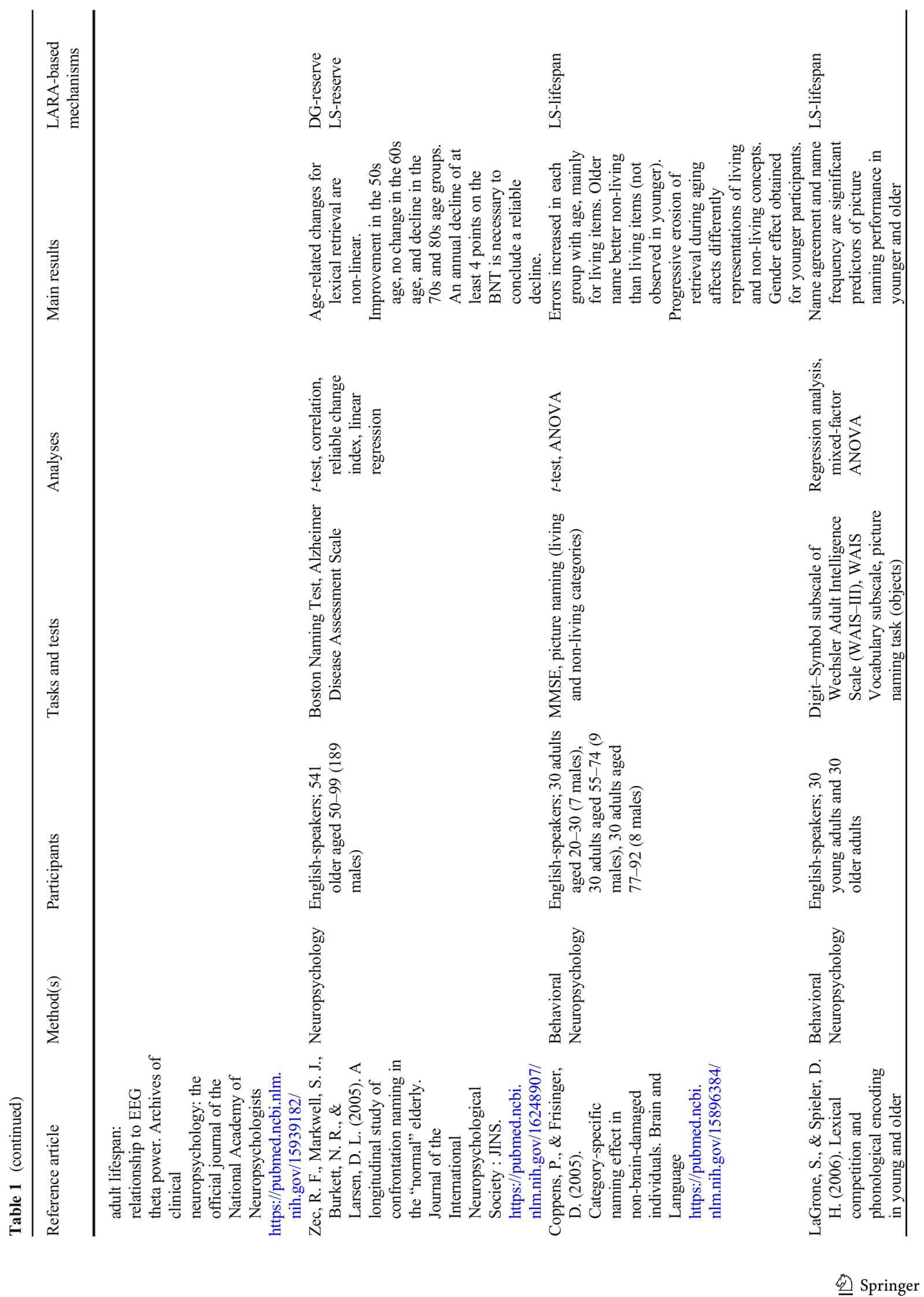




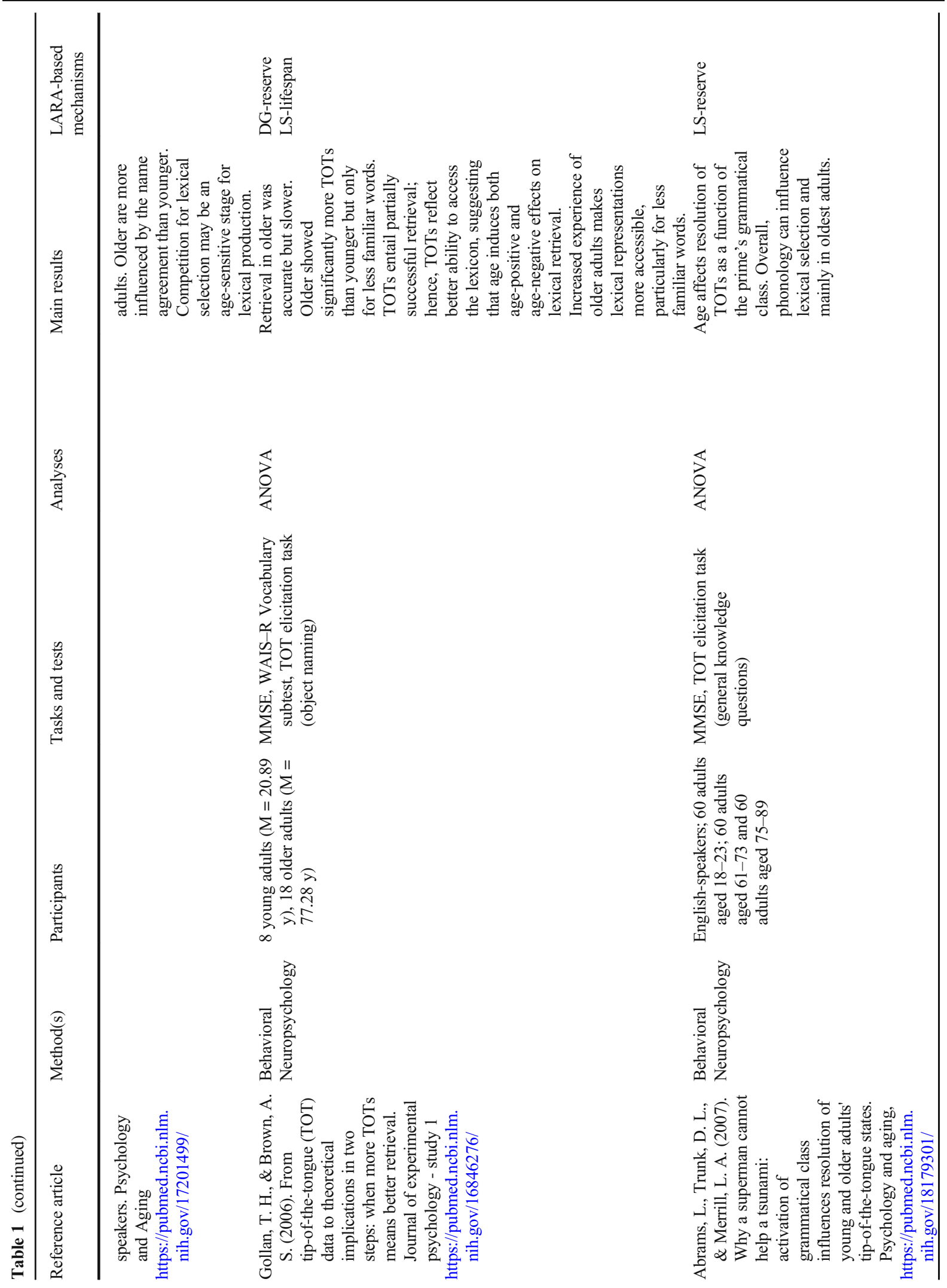




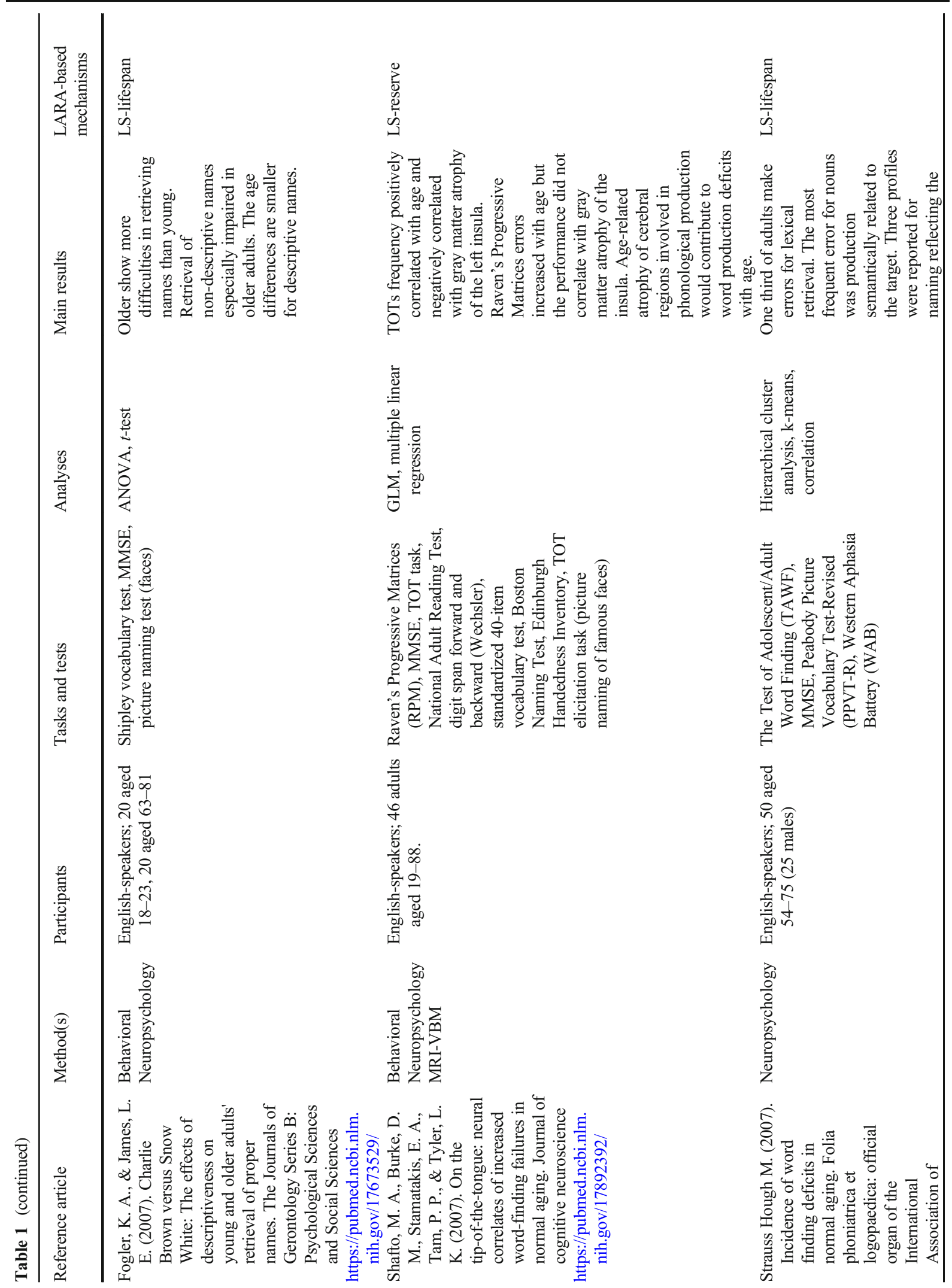




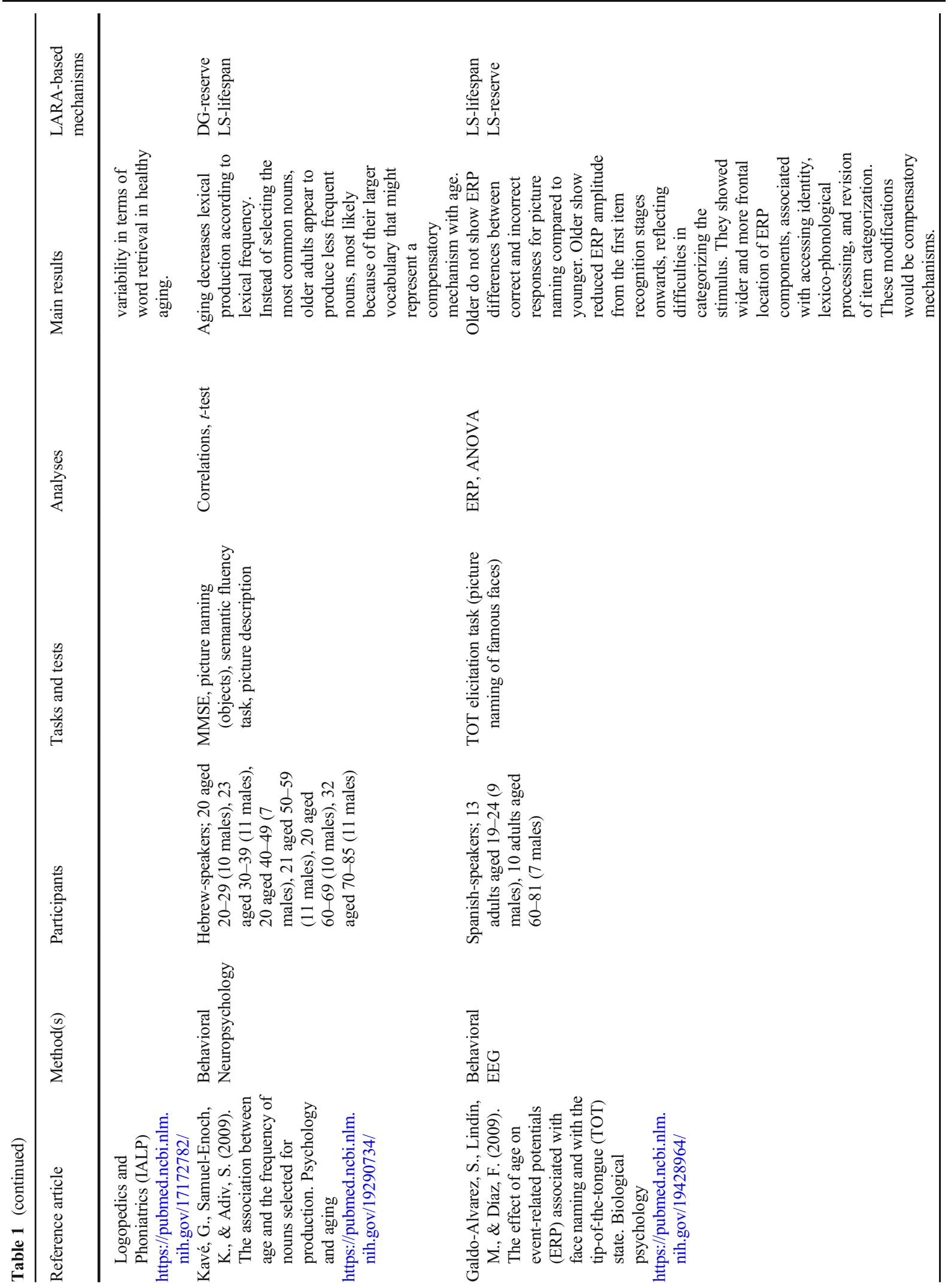




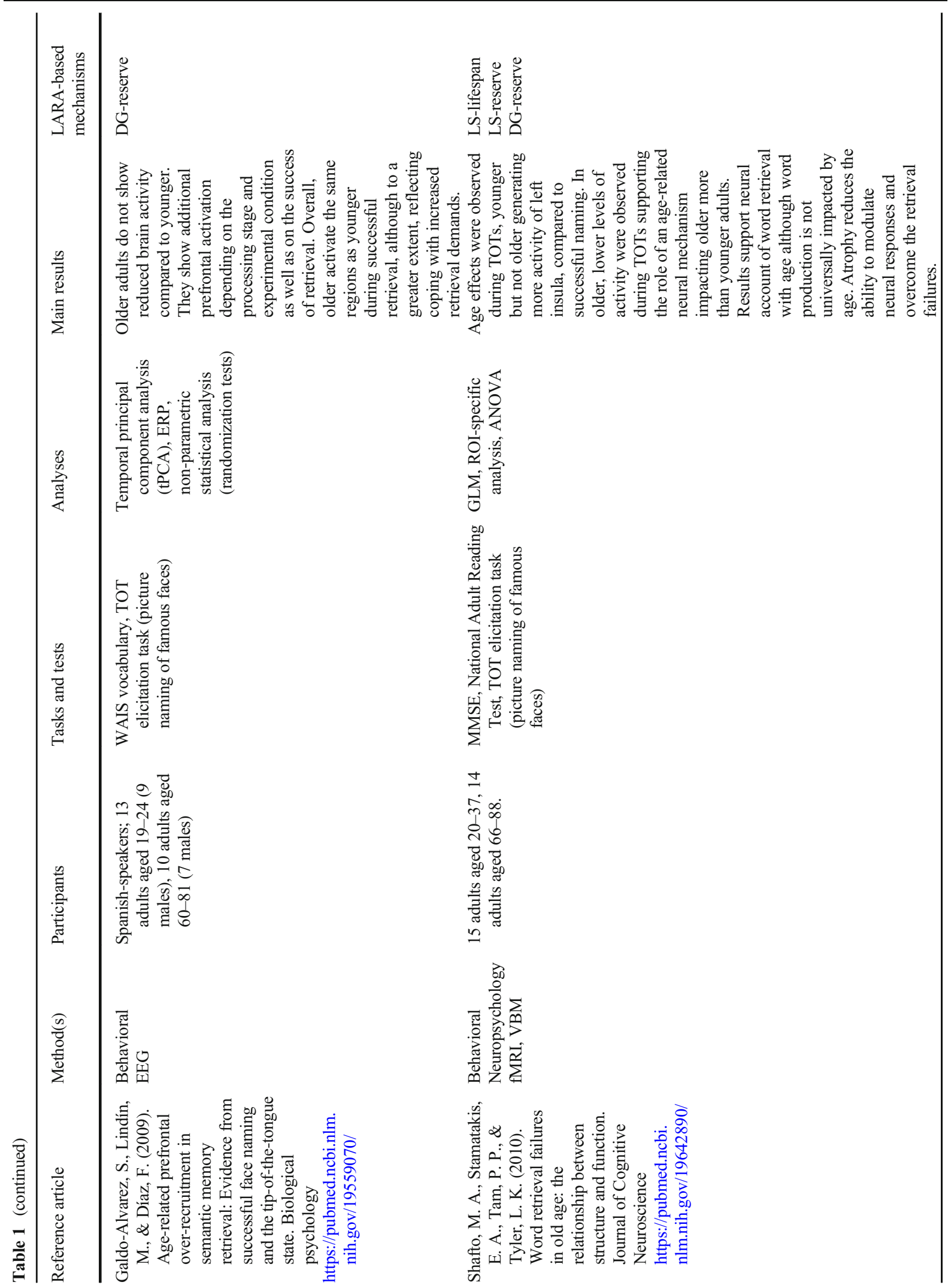




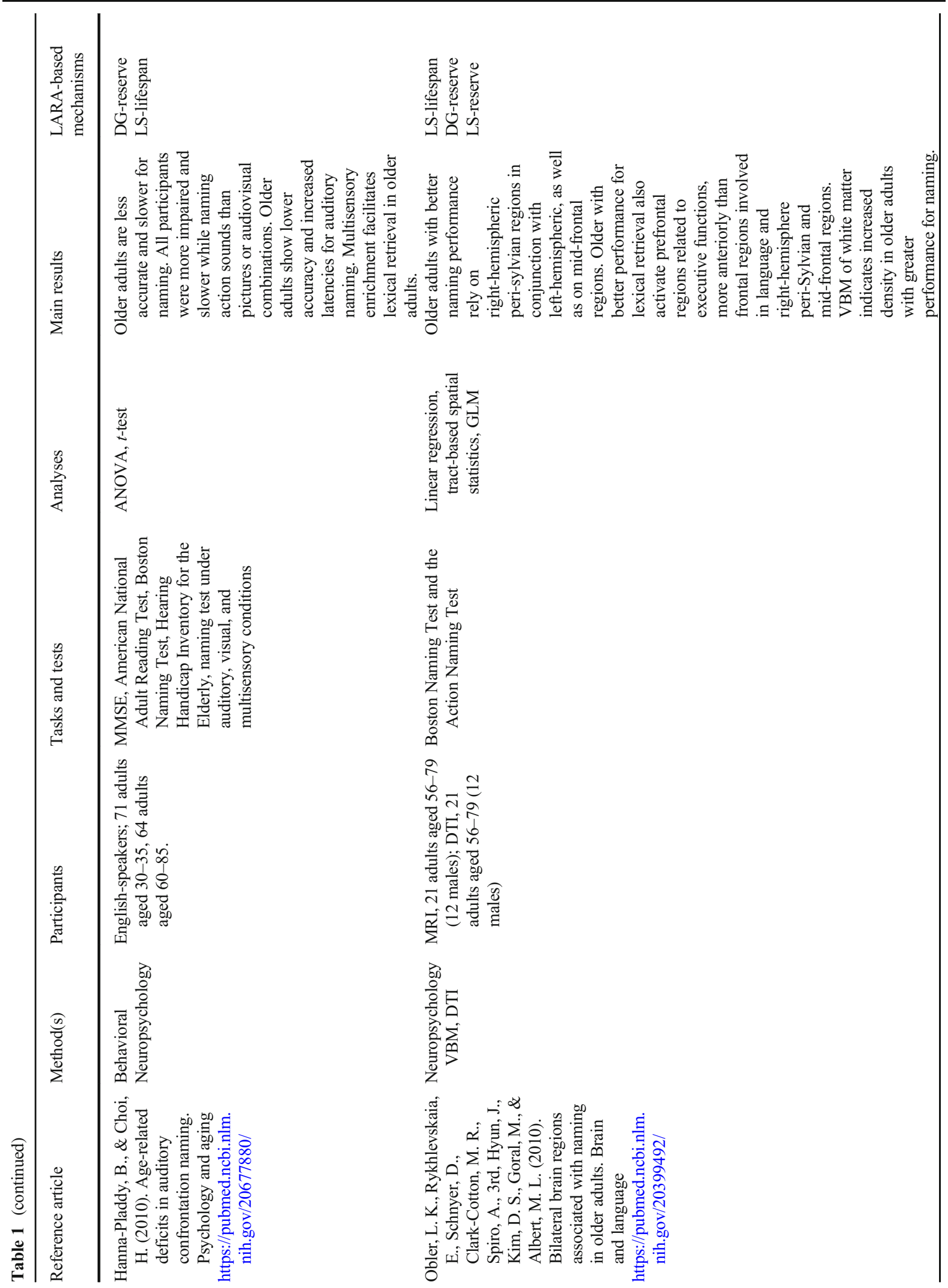




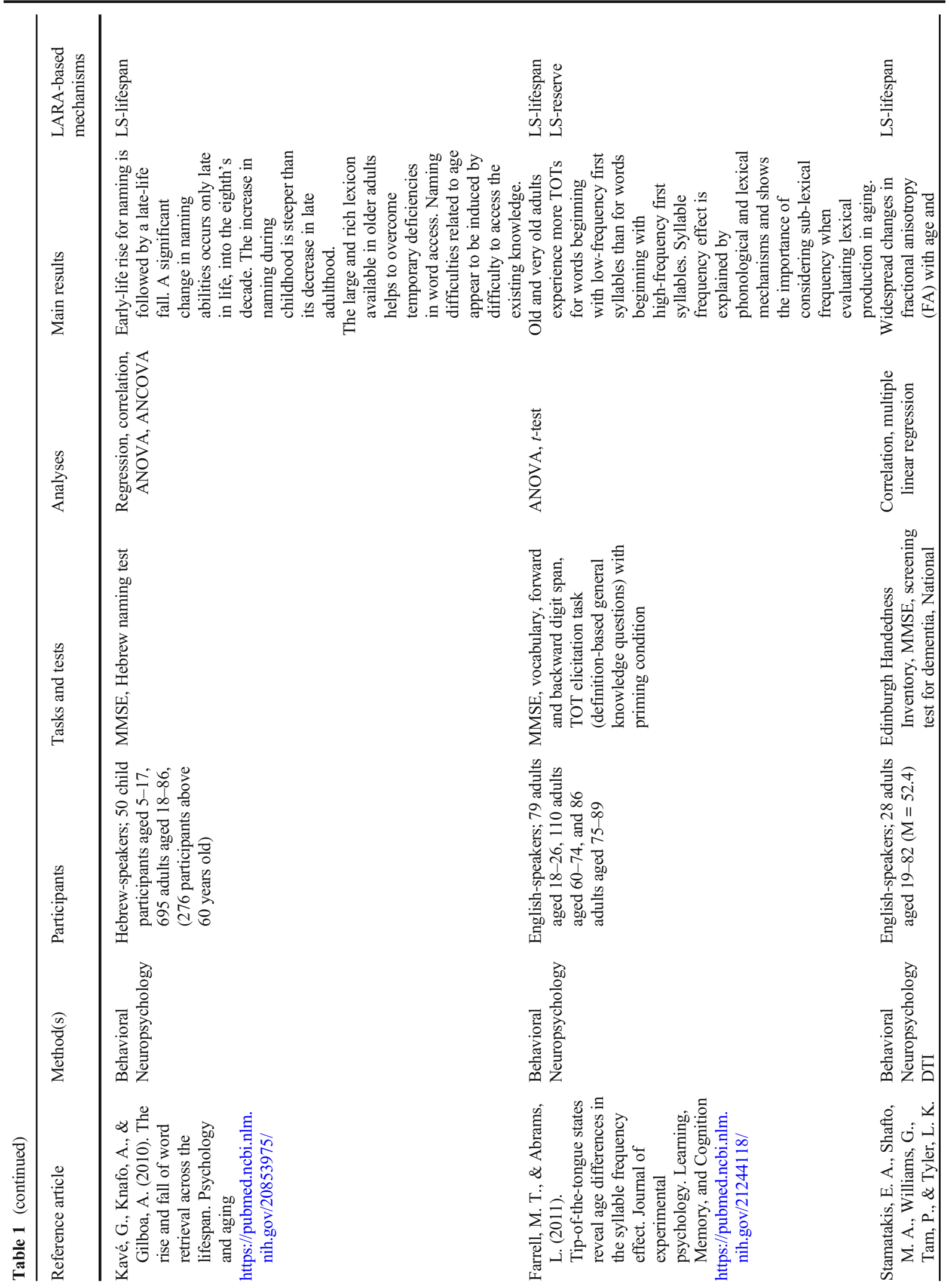




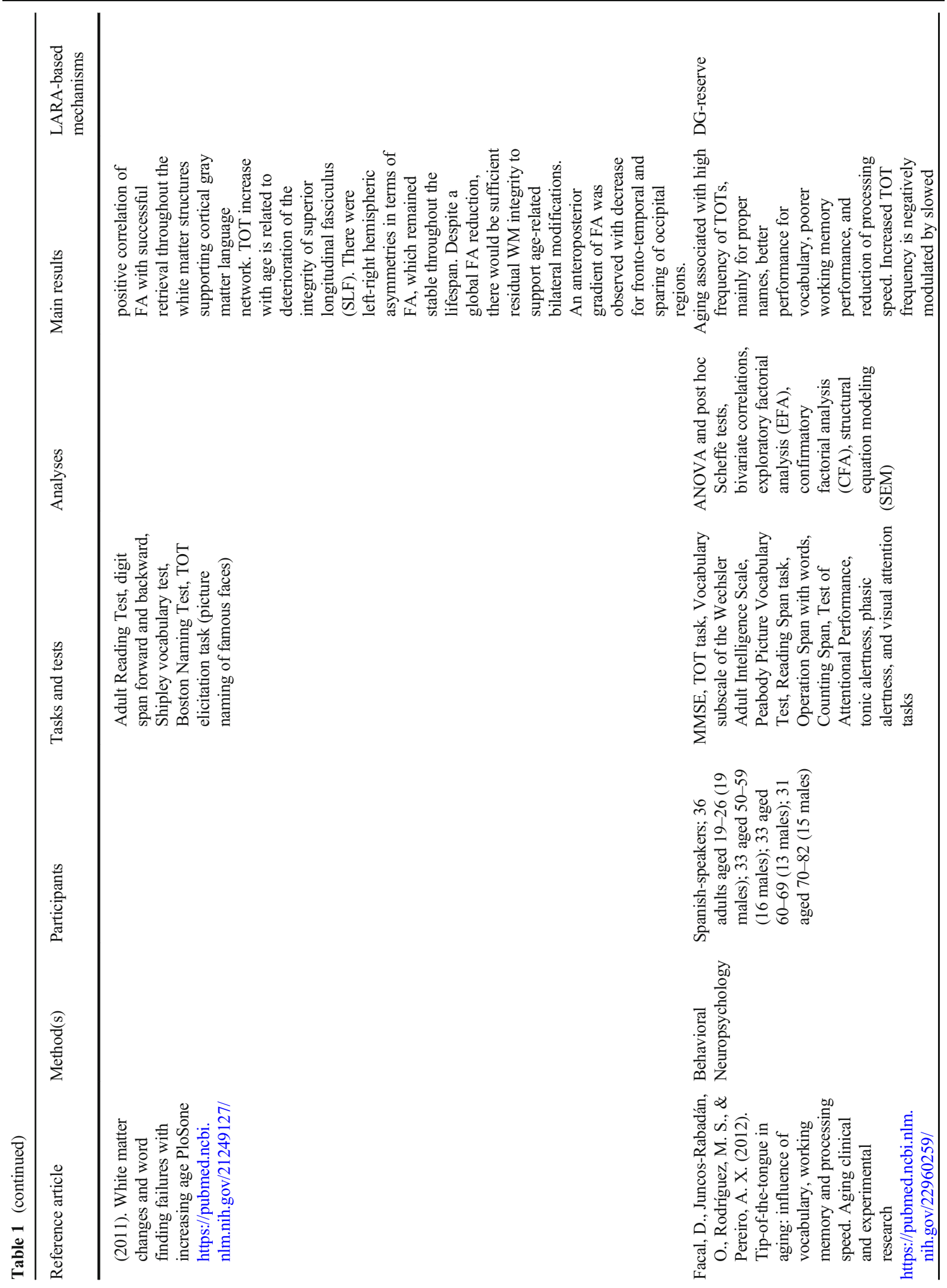




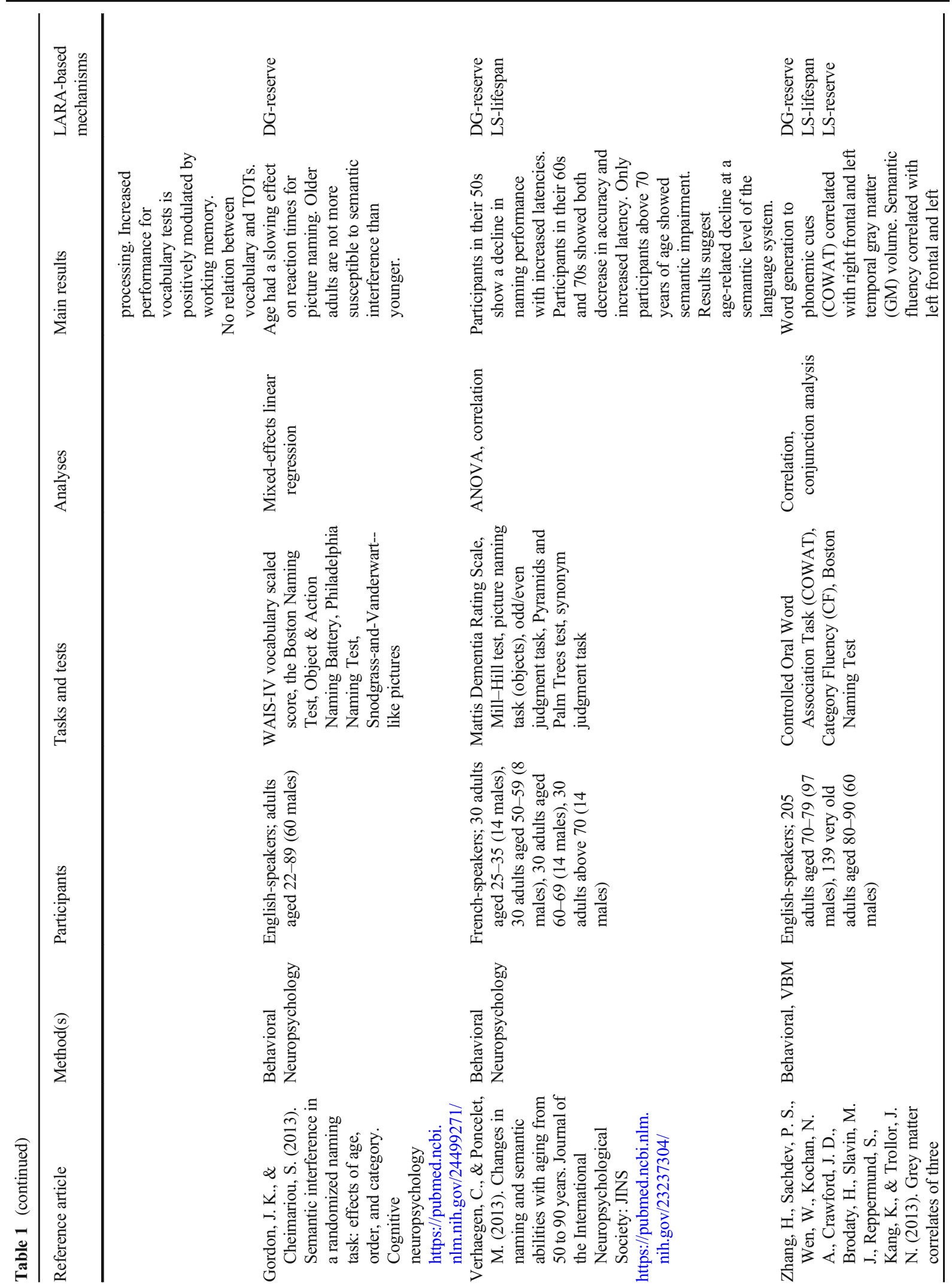




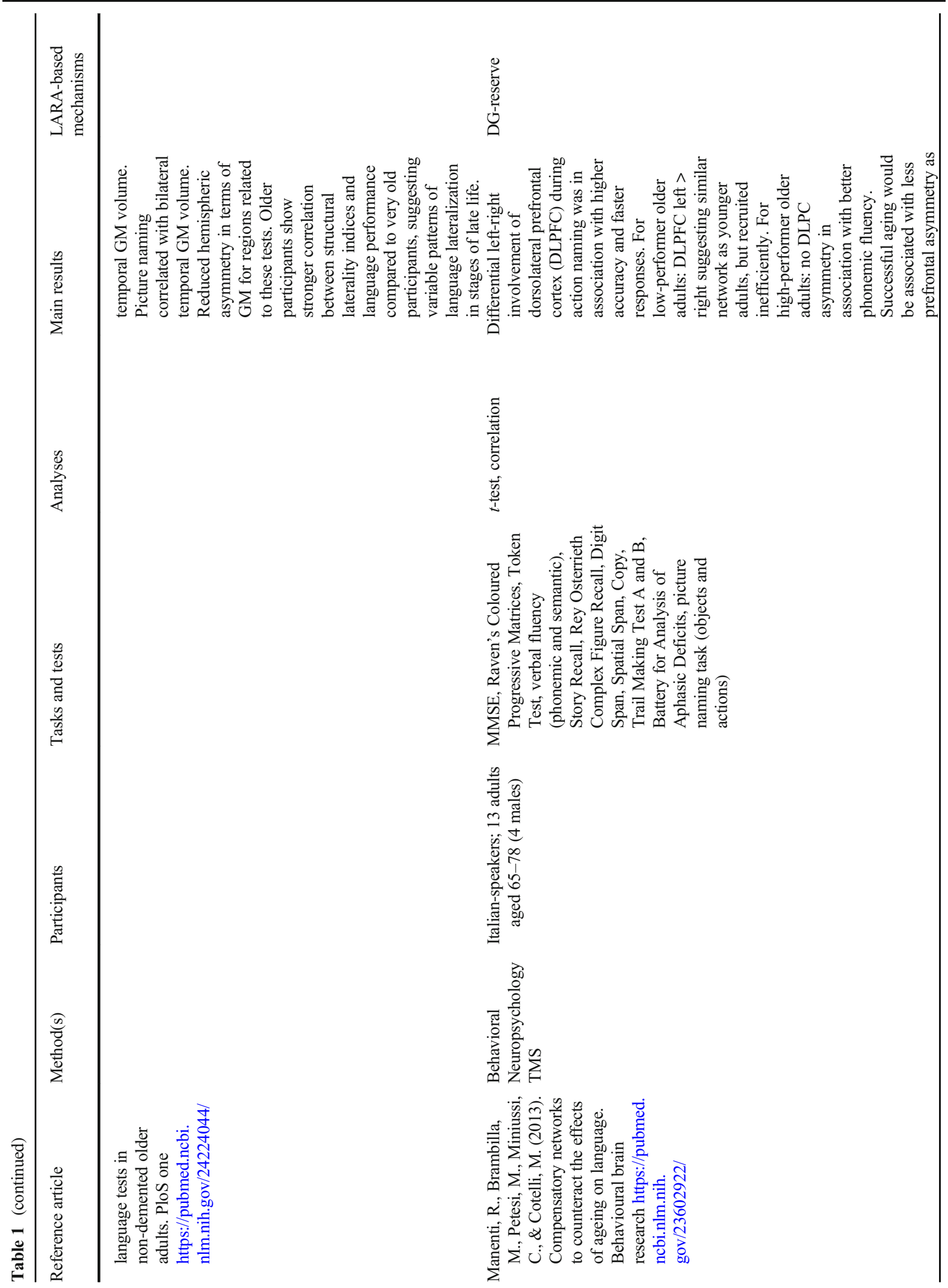




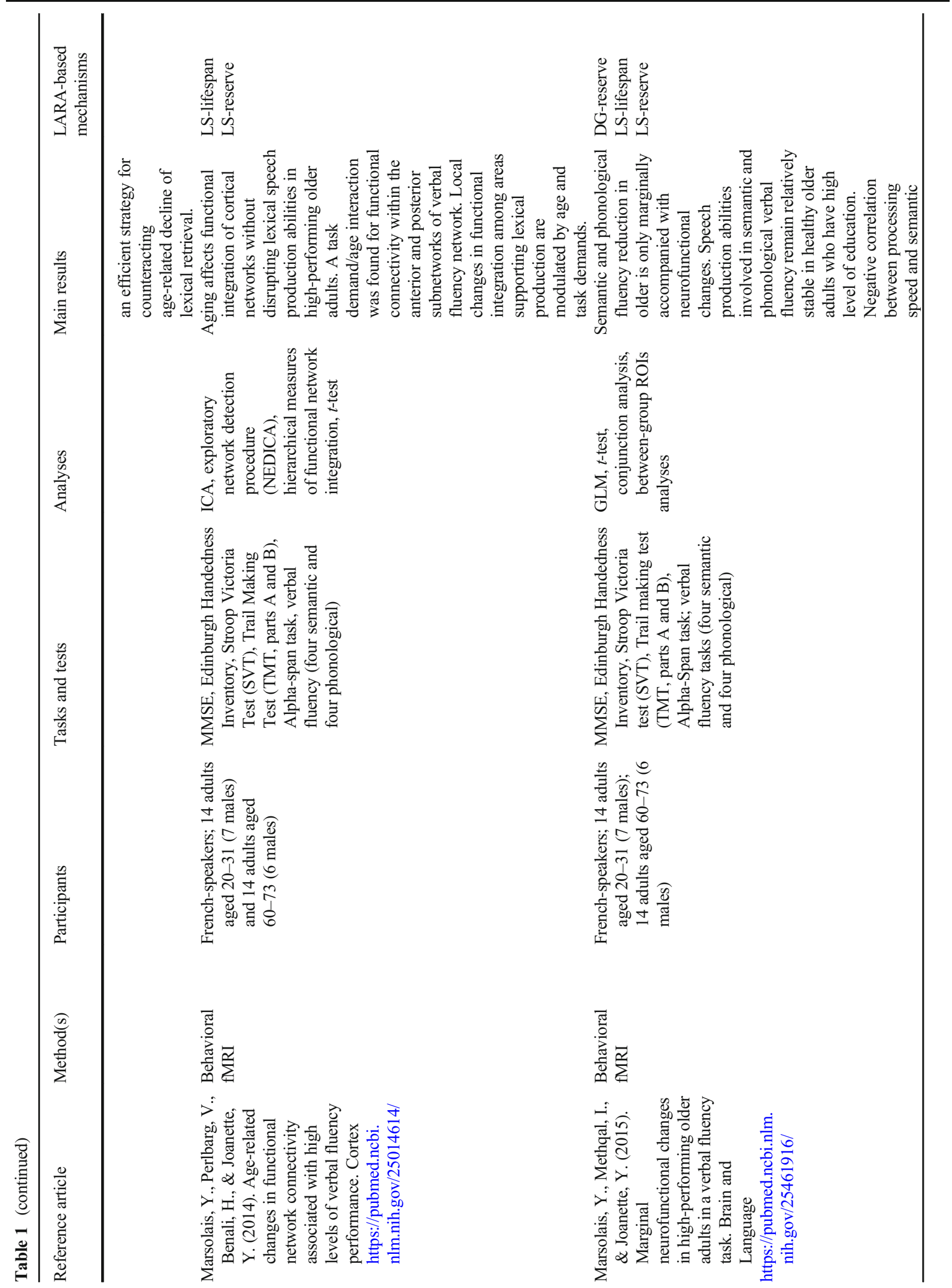




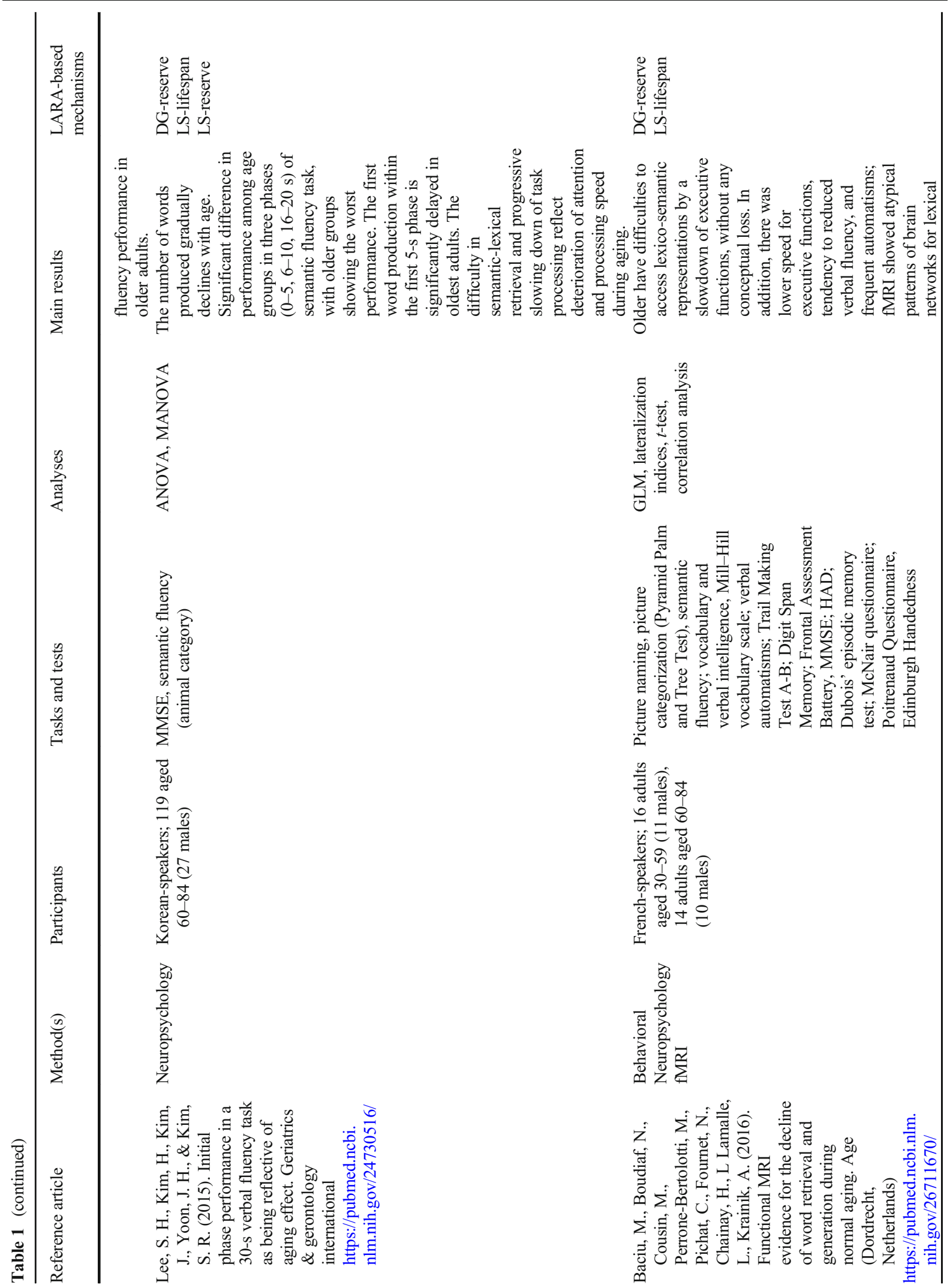




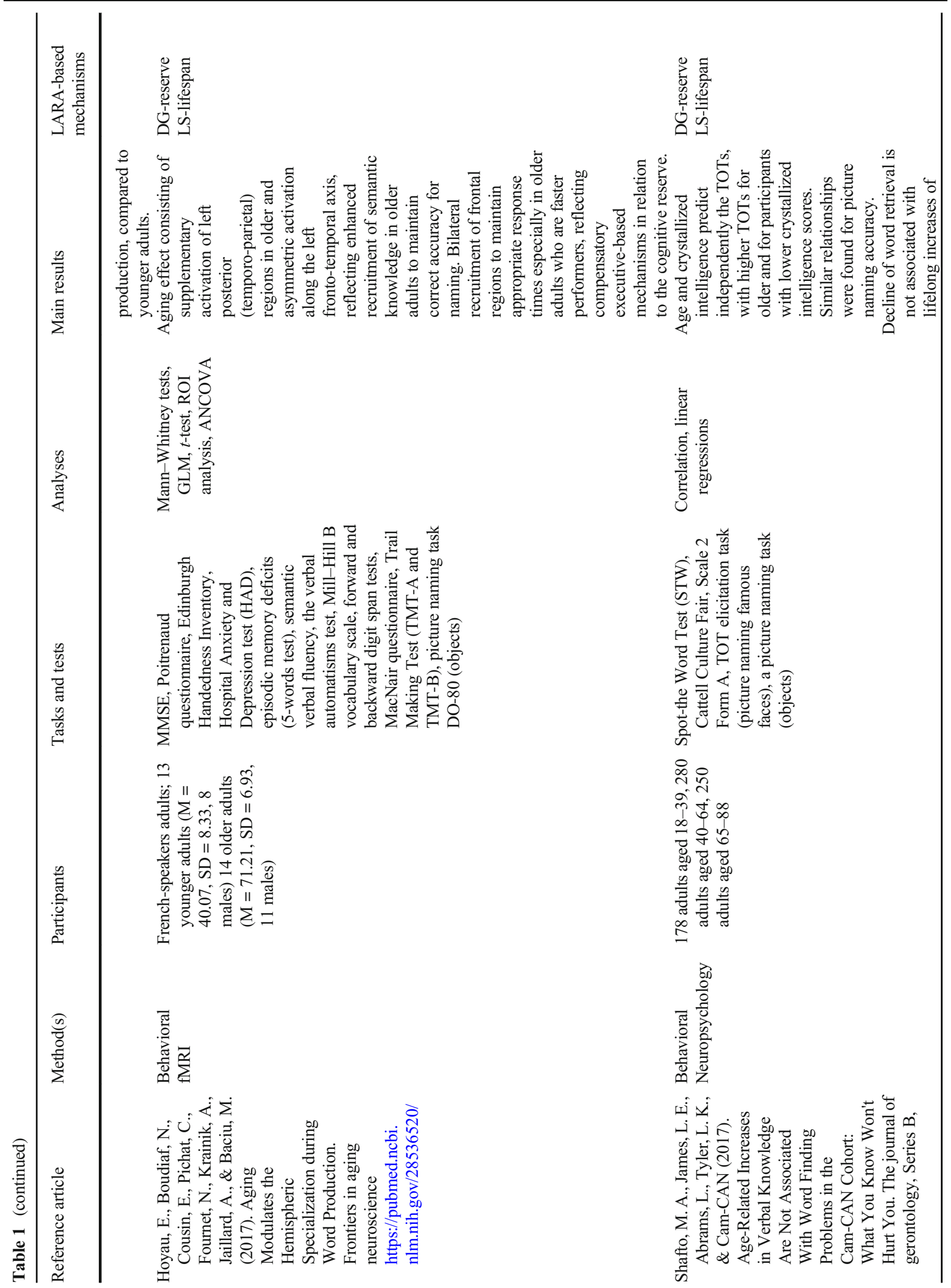




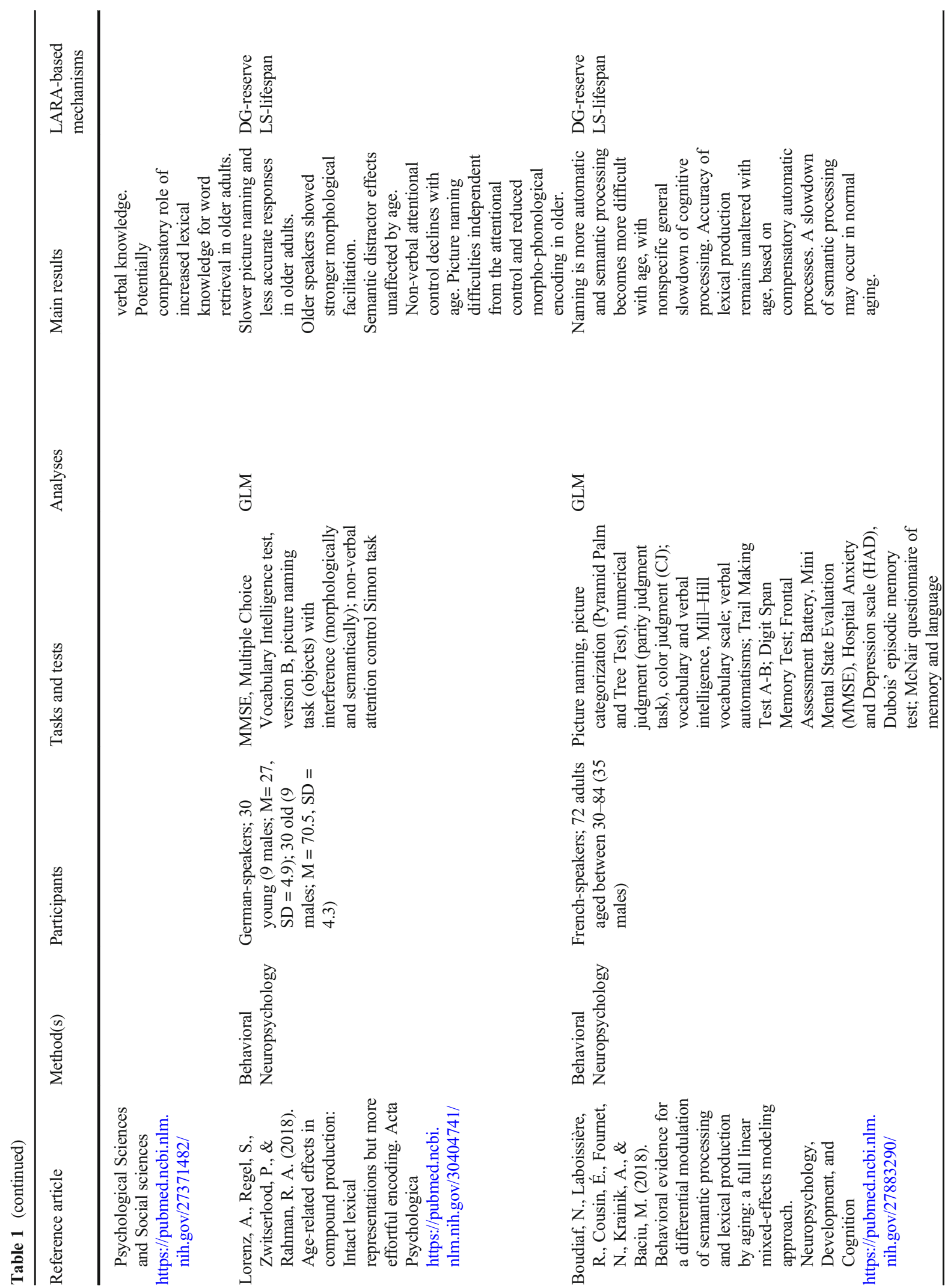




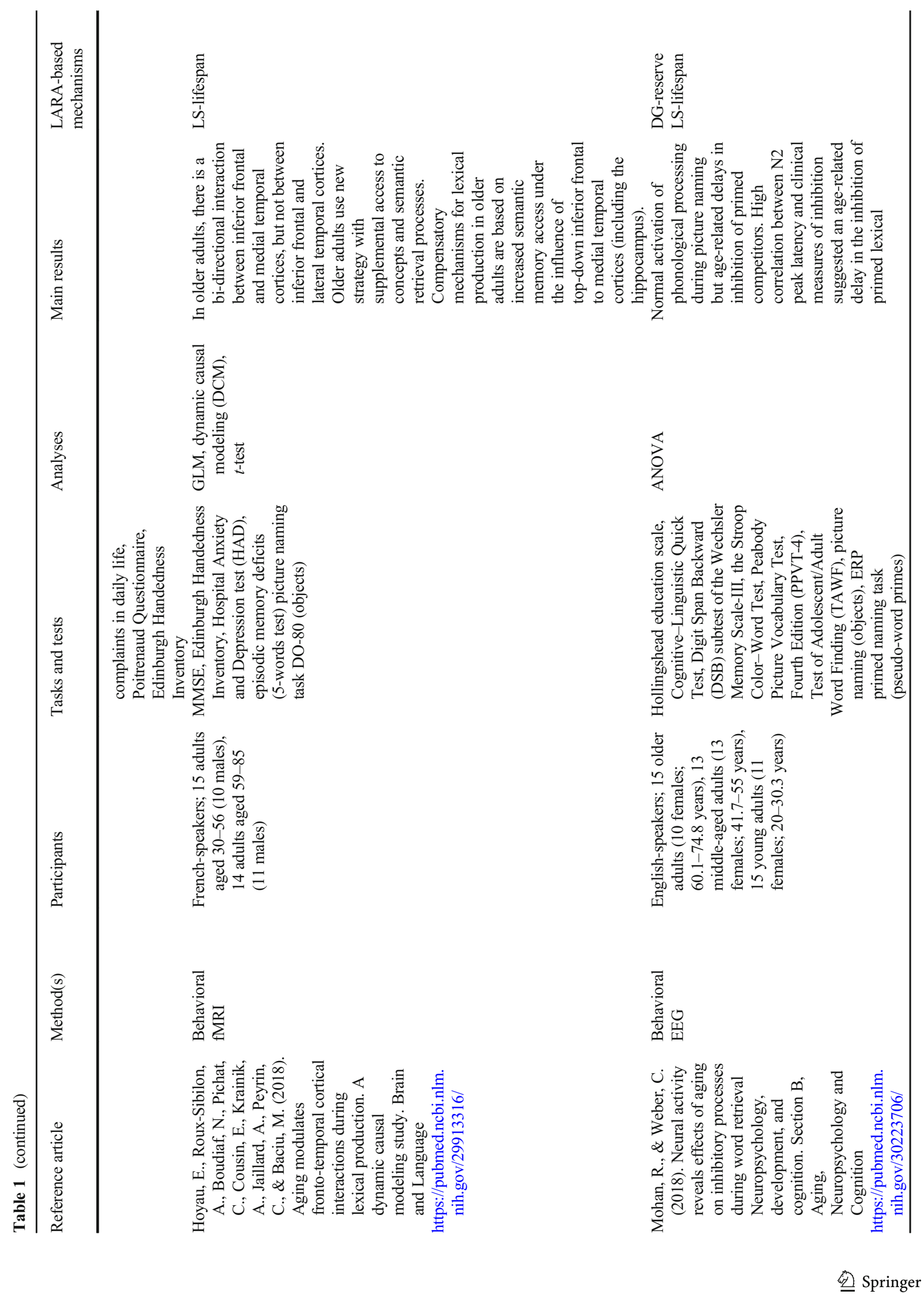




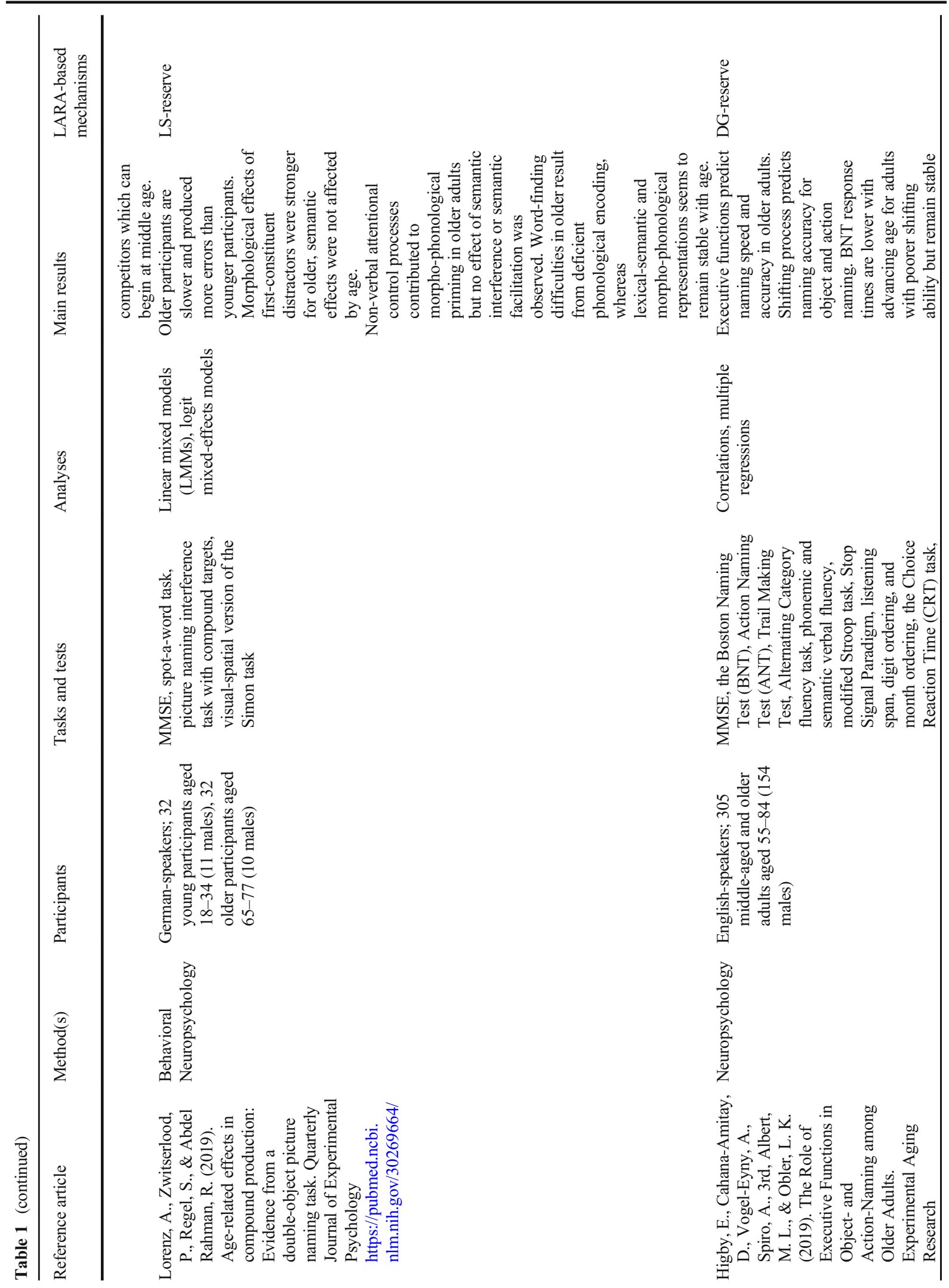




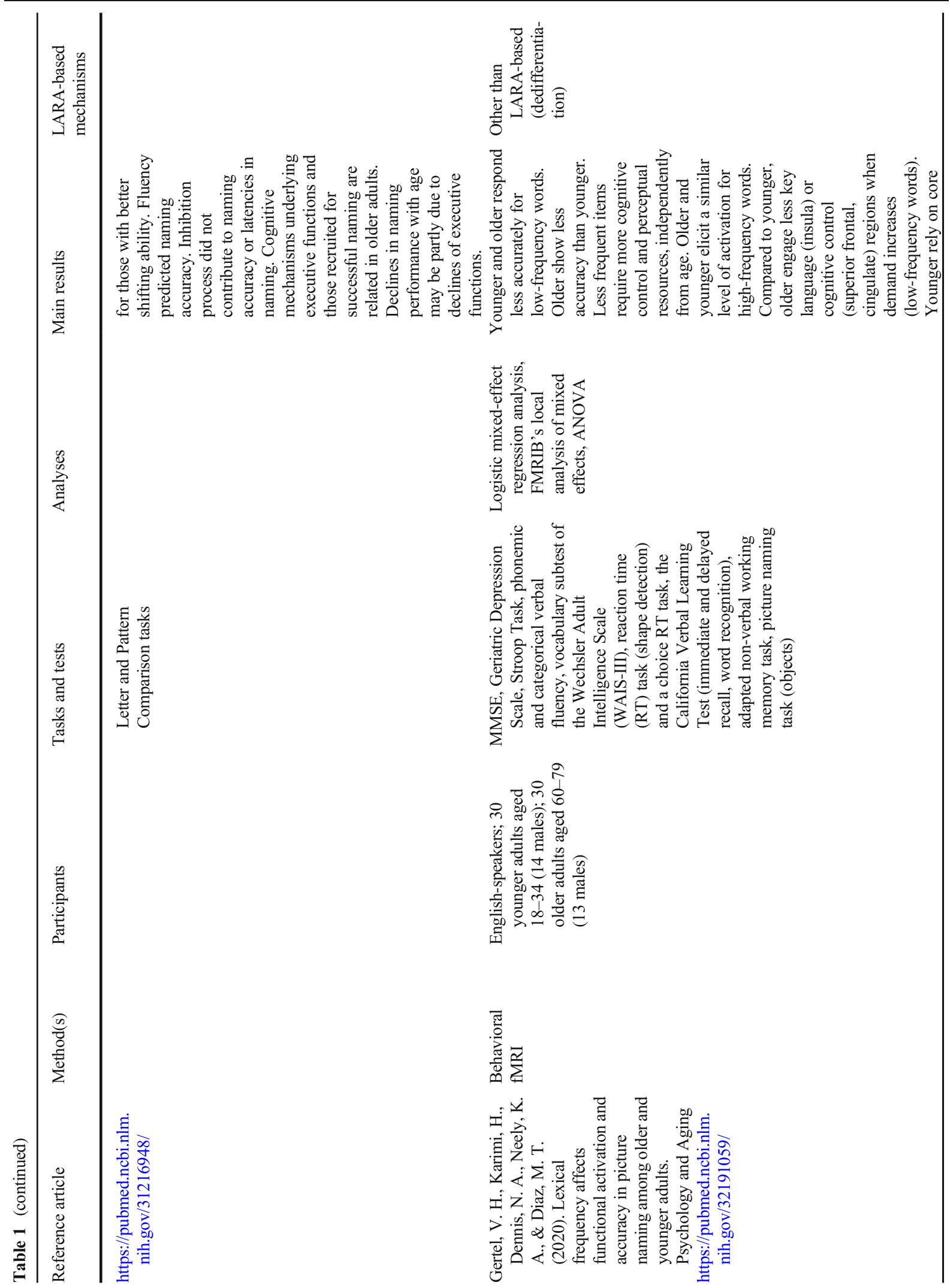




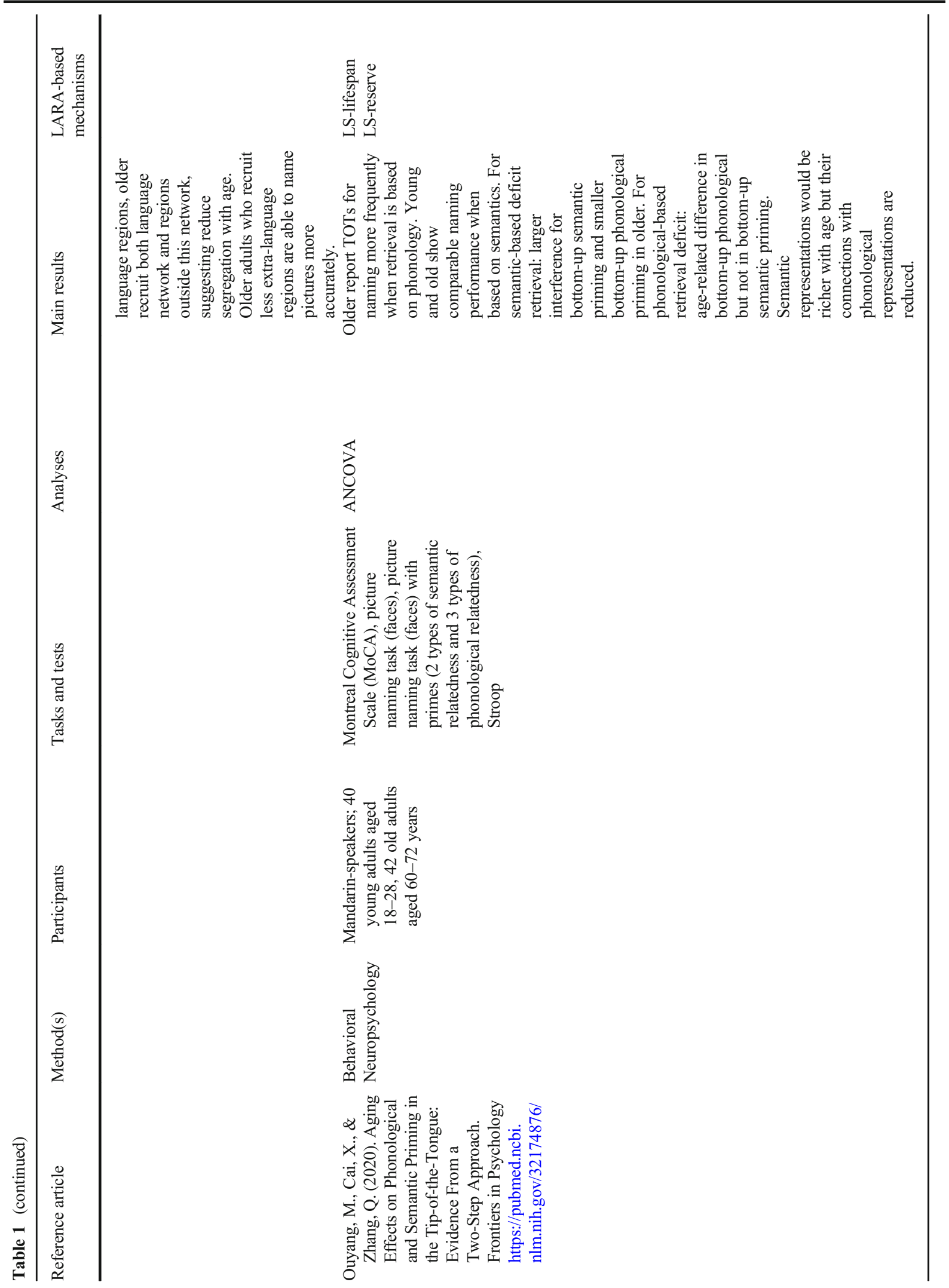


processing speed, which results in operations prevented from being successfully executed or chained due to limited time [155]. The links between processing speed decrease and cognitive inhibition deficits have been debated $[75,113,158]$. Some studies suggest that naming deficits can be explained by difficulties to select an appropriate word among a set of similar alternatives [9, $101]$ or to inhibit non-pertinent competitors [67, 131]. A decline in attention and working memory has also been incriminated $[27,104,130]$ as a potential source of word production deficit. Altogether, the studies reviewed above reveal that uncovering the mechanisms responsible for cognitive aging is challenged by the facts that age has heterogeneous effects on different cognitive processes and that cognitive aging does not manifest uniformly in the general population.

\section{Universal vs. idiosyncratic aging}

Even though a universal decline in specific cognitive functions is manifest in all individuals as they grow older, the degree of decline varies from one individual to another. Comparison between older and younger groups is the commonly used approach to assess the effect of age on cognitive processes. It is generally observed at a group level that behavioral and cognitive performance scores in older adults are lower when compared to younger groups, reflecting a universal effect of age. However, among the older adults, a significant inter-individual variability may be observed, reflecting a non-uniform or idiosyncratic effect of age, some aging adults being cognitively more efficient than others and for longer periods [28, 32, 185, 191]. Understanding this variability is particularly important for identifying risk and preventive factors associated with cognitive aging, in order to promote successful aging. More specifically, healthy aging can in fact be described as either successful or usual/common $[152,153]$. Successful aging, also called optimal health or super-aging [184], is associated with a low probability of disease or disability, high cognitive and physical function, and active engagement in social activities, while usual/common aging describes good cognitive and physical performance levels but higher risks of disease or disability [152]. Even if the theoretical concept of successful aging has been questioned because of the difficulty to find a consensual definition and implementation [36, 120], it offers a more positive prospect on aging and has opened a line of research focusing on the biological and lifestyle factors that may favor a more performant aging $[10,200]$.

Cognitive aging, reserve, and compensatory mechanisms

The inter-individual variability in aging is generally explained by the notion of reserve [182] with two complementary dimensions $[13,183]$, one passive or cerebral $[92,159]$ and another active or cognitive [182]. The cerebral reserve is described as the amount of brain deterioration that can be tolerated before reaching a critical threshold, above which functional consequences are unavoidable. On the other hand, cognitive reserve, an active mechanism which may explain some interindividual variability, refers to the ability to efficiently use the available cerebral reserve to perform a specific task. Two implementations of the cognitive reserve have been proposed, neural reserve, i.e., the optimized use of typical predefined networks for a given cognitive process, and neural compensation, i.e., the use of alternative networks than those classically predefined for a specific cognitive process $[13,183]$. Large cognitive reserve suggests more flexible cerebral networks and greater ability to adjust behavior to the task constraints [15].

Cognitive reserve, be it neural reserve or neural compensation, is related to the reorganization or plasticity of cerebral networks, either intrinsic, which are observed in the absence of cognitive tasks (rest), or extrinsic, which are required by cognitive tasks. In the absence of any specific task, the intrinsic activity is represented by several distinct and distributed functional subnetworks or modules, involving several brain regions which are connected with each other [205]. Among these modules, one can mention the default mode network (DMN; [123, 143, 172]), executive control, salience, sensorimotor, and visual networks $[109,176]$. The modular organization may offer a protective mechanism in the case of injury [58]. Moreover, these intrinsic networks evolve under the effect of age toward a decrease in network segregation, as has been observed in older participants [29, 63]. A recent longitudinal study [117] performed on a 4-year period showed significant reconfiguration of these networks in healthy older adults, with significant network flexibility between modules, even if the authors did not find a correlation with cognitive performance. Other studies focused on variations in the activity of the default mode network with age. The DMN is associated with a variety of functions such as semantic processing 
$[19,206]$, mind-wandering [121] and, more generally, with internally generated cognitive operations [4, 72]. With normal aging, DMN activity is modified in terms of either reallocation of activity within DMN regions $[125,146]$ or changes in the magnitude of DMN deactivation [21]. Another line of research has revealed disrupted functional connectivity (FC) within the DMN and reorganizations of the connectivity between and within large-scale cognitive networks [154]. Specifically, FC decreases with age [5, 38, 50, 69, 202, 209] and older individuals show reduced brain connectivity $[5,70]$. In the same line, Li et al. [108] showed modifications of functional and structural connectivity reflecting increased bilateral prefrontal recruitment, as a compensatory mechanism that may counteract agerelated unilateral efficiency decline. Krieger-Redwood et al. [100] showed that behavioral changes with age for a semantic control task are correlated with measures of intrinsic connectivity between the anterior temporal lobe and medial prefrontal cortex within the DMN. Authors showed that compared to younger individuals, older adults showed reduced connectivity between the right anterior temporal lobe and medial prefrontal cortex and this decrease in connectivity was correlated with preserved verbal semantic performance but reduced semantic retrieval control. The patterns of functional changes in prefrontal regions implicated in cognitive control together with modifications in the DMN led Spreng and colleagues to propose the DECHA model (Default-Executive Coupling Hypothesis of Aging; [180, 181, 194]). In the DECHA model, it is claimed that older adults fail to modulate functional connectivity between executive control regions and the DMN in response to increasing task challenge, relying more on stored semantic knowledge (DMN) and less on executive control. This would be reflected in reduced DMN suppression during goal-directed tasks and an increased inflexible coupling with lateral prefrontal executive networks, in older adulthood. In the same line, Muller et al. [127] found that a finely coordinated interaction between DMN, executive-control, and language networks is crucial for successful verbal fluency performance in older adults. Furthermore, He et al. [77] quantified dynamic reconfiguration of several resting state functional networks in adults of different ages and showed differential modifications of segregation and integration with age. Reduced dynamic segregation was observed for all networks with age, except for the cerebellum. Aging increased dynamic integration of several intrinsic networks, such as the DMN, FPN (fronto-parietal network), and visual network. According to the authors, these findings suggest a significant modulation of the intrinsic activity of aging brain networks, reflecting agerelated adaptive dedifferentiation (reduced neural specificity) and compensation mechanisms. This might contribute to maintaining cognitive performance through the modulation of cognitive reserve. These findings are in line with other studies which found increased between-network connectivity and reduced withinnetwork connectivity [29, 31, 95], supporting the idea of increased integration with compensation and reduced segregation with dedifferentiation during aging.

Other brain reorganization patterns have been observed in older adults, at an intra-hemispheric level, such as the Posterior-Anterior Shift in Aging (PASA) model [39, 42] assuming reduction of activity of posterior occipito-temporal regions with increased frontal activity. Hoyau, Roux-Sibilon, et al. [84] examined if the compensatory strategies associated with the effect of age on the effective connectivity of lexical production networks would pertain to a neural reserve mechanism (reflected by increased connectivity between the medial temporal cortices including the hippocampus and lateral temporal cortices), or to a neural compensation mechanism (reflected by increased connectivity between the inferior frontal cortex and medial temporal cortex). While younger adults showed bidirectional interaction between left inferior frontal and left temporal cortices, suggesting recruitment of lexico-semantic representations, older adults showed bi-directional interaction between inferior frontal and medial temporal cortices, but not between inferior frontal and lateral temporal cortices. These results suggested that older adults develop compensation strategies facilitated by top-down mechanisms from inferior frontal to medial temporal cortices. Another compensatory mechanism observed in older adults is described by the HAROLD (Hemispheric asymmetry reduction in older adults) model of cognitive aging. Namely, during the performance of various cognitive tasks, older participants show a reduction of hemispheric asymmetry in comparison to younger adults [28]. This pattern is especially patent in high-performing older adults [118]. It could represent the use of either cerebral or cognitive reserve, at regional or network levels. 
Aging-modulatory reserve factors (AMF)

Available evidence on inter-individual variation in vulnerability to cognitive decline [91] reveals resilience mechanisms that need to be better understood in order to prevent pathological aging and neurodegenerative conditions.

In recent studies, more attention is drawn to agingmodulatory reserve factors (AMF), various elements that can modulate reserve, either increasing it or acting as a potential risk for pathological aging. In general, aging can be described as a result of the interaction between genetic and environmental factors [96]. In the case of damage or tissue loss and reduced functionality of organs, this interaction will manifest through a decrease in performance, including cognitive decline.

The notion of consilience, the independent converging agreement of explanations at various levels, supports the theory construction of health and by extension, to cognition. In the domain of aging, it might suggest that the effects of a specific modulatory factor are exerted at various levels, from molecular genetics, epigenetics, sub-systems to higher complex and dynamic interactions between cognitive systems. Indeed, a specific modulatory factor may affect the relations between cerebral functions from perception to high-level cognitive processes, from a molecular to a cerebral and cognitive level, in tight relation with social and environmental factors (for details, see [163]).

It is beyond the scope of the present paper to provide an exhaustive description of studies on modulatory factors of cognitive reserve and normal aging. Therefore, in Supplementary Table (Annex), we present a synthesis of main studies on AMF and their relation with cognitive aging. This synthetic presentation of main studies was conducted using the PubMed database during November 2020 for a systematic literature review of age-related lexical changes in lexical production. Keywords used were "aging/ageing", "reserve", "healthy", "cognitive" in the following combination: (aging OR ageing) AND reserve AND healthy AND cognitive. Two of the authors first screened the titles and abstracts of the resulting papers to assess their eligibility and then performed full-text scans to determine whether papers met the inclusion criteria. To be included in the review, the studies had to fulfill the following inclusion criteria: published between 2000 and 2020, written in English, the study includes older participants (60+), and the study specifically assesses the modulatory factors of the cognitive reserve during aging (i.e., not just effects of the cognitive reserve). The studies were left out if they fulfilled one of the following exclusion criteria: participants suffered from some form of pathology, results reported on very low statistical level (i.e., $p<0.1$ ), and the majority of participants were middle-aged $(<60)$. Case studies, meta-analysis, and review papers were excluded. Through this process, 48 papers were identified, some of them (in green) being mentioned several times, for several tested AMF. In the next section, we describe the main mechanisms considered to be involved in lexical production decline.

Genetic predisposition and biological factors play a significant role in the neuroplasticity observed during aging. For instance, the catechol-O-methyltransferase (COMT) genetic polymorphism has been brought up. Indeed, carrying less favorable combinations of alleles leads to poorer cognitive performance during aging [48, $122,192]$. Similarly, carrying the $\varepsilon 4$ variant of ApoE is a risk factor for Alzheimer's disease and this variant seems to be more frequently associated with increased risks for poorer functional status ([3]; see Supplementary table for specific relationsof the APOE- $\varepsilon 4$ with cognitive activities) and reduced cognitive performance ([24, 44] cited by [175]). Positive associations have been found between social activities and the ADRB2 genotypes, with a favorable effect on health and longevity [208]. Moreover, the brain-derived neurotrophic factor (BDNF; see Supplementary Table) gene and expression of BDNF protein are particularly important for cognitive aging. The BDNF has a significant effect on the brain and cognition, based on synaptic plasticity, neurogenesis, memory, and neuronal stress resistance (see [119] cited by [163]). It has been observed greater cognitive decline in older individuals carrying less favorable combinations (Met variants) of alleles [49, 94, 136]. We mentioned above the stress as a significant factor that may affect global health and cognition. The stress would target the level of BDNF. BDNF is a potent neurotrophic factor and its reduced levels were identified in normal aging and neuropathological conditions (e.g. Alzheimer's disease) in which its downregulation was related with neuronal atrophy and death [129]. Chronic stress can contribute to age-related changes by decreasing hippocampal BDNF expression [174]. Other genetic factors have been incriminated, such as genetic polymorphisms of the kidney and brain expressed protein (KIBRA; [93, 164]) and of the dopamine D2 receptor (DRD2; [139]) genes. In terms of biological factors 
and as mentioned in the Supplementary table, the cerebrovascular reserve, the integrity of noradrenergic system, and the initial size of the hippocampal volume, as well as vascular health, showed a significant effect on cognitive abilities during aging.

Environmental factors can also show significant effects on cognitive aging. Social interactions can have a significant role in improving mental health and general well-being [190]. In addition to physical interactions, virtual interactions (e.g. via social media) can help older people in dealing with stress and loneliness [105].

Overall, as mentioned in the column "Cognitively stimulating activities" (Supplementary table), education [3, 10], occupational status [142, 189], premorbid IQ estimation, and engagement in stimulating physical [140,148], intellectual, and leisure activities [83, 178, 201], as well as a balanced diet and nutrition [54, 56, 57], might all have a neuroprotective role in aging. The wide concept of "activity" includes both social interactions with one or more people and more solitary activities such as reading or gardening [124]. Participation in leisure social activities seems to have a beneficial role on executive performance [151], and it is associated with a lower risk of developing dementia [197]. Regarding lexical production and aging, a recent study [83] found a positive correlation between the frequency of group activities and naming performance, as well as between social activities and left superior and medial frontal gyrus activation during picture naming. These results suggest that social leisure activities may contribute to maintaining the lexical production performance in older adults, through the neural and cognitive reserve mechanisms mainly dependent on the left prefrontal cortex. This region and particularly the superior medial frontal gyrus are involved in accessing semantic representations that can be guided by the emotional state. These results coincide with current studies showing a positive impact of emotional qualities of social activities [20] on global well-being and cognitive aging of older adults. We claim that regular practice of social leisure activities would modulate behavior, as well as brain activity, probably by boosting the affective drive and improving the efficiency of lexicosemantic search processes. Such activities require people to communicate more which results in more training. When people meet together, they are expected to talk and share ideas. Therefore, they can be expected to use language more than when they are not interacting with other people. This way, they regularly train their lexico-semantic search. In addition to positive effects related to emotion processes, the relation between the frequency of participation in social activity and language production scores may also be explained by preserved perspective-taking skills which might be beneficial. Perspective-taking refers to the ability to adopt the point of view of other people. It has been suggested that perspective-taking may be considered as a strategy to strengthen social bonds and is beneficial in several ways, for instance by favoring social coordination through increasing self-other overlap [62] which facilitates interhuman communication. Other explanations can be taken into account. According to Eyme et al. [52], a more active lifestyle in general is associated with increased gray matter volume in frontal areas associated to self-awareness and working memory. Additionally, many studies show a beneficial effect of social engagement on the protection against cognitive decline [14, 89, 173]. Specifically, social network size mediates the relation between an active lifestyle during middle adulthood and better cognitive functioning in old age [160]. In addition, a recent review showed that foreign language learning even at an advanced age has a positive impact on the maintenance of cognitive abilities, probably also via better socializing and integration into society, with a positive influence on their well-being [97]. However, the underlying factors that are responsible for the observed beneficial effects remain to be understood. Previous studies proposed stress prevention [60], reduction of depressive symptoms [37], forms of cognitive enrichment [79], and cognitive reserve [161]. In addition, emotional regulation processes could also play an important modulatory role between social activities and cognitive aging. Conversely, habits such as smoking or an inappropriate diet that can lead to biological dysfunctions can also have a deleterious effect on cognition during aging. Typically, high blood pressure and cholesterol, as well as diabetes, induce cognitive decline during aging (see $[6,7,177])$. The role of environmental factors, beneficial or deleterious, may be reflected in BDNF protein secretion which respectively 
stimulates or inhibits endogenous neurogenesis, especially during aging $[65,186]$.

Bilingualism and education are factors that showed modulation of various cognitive functions, even if the results are not consistent among authors. As mentioned in Supplementary Table and illustrated by the results of several studies that found such modulations, speaking two or several languages would improve executive and visuo-spatial functions and would delay the onset of neurodegenerative disorders of several years, by improving the cognitive reserve. Interestingly, early bilingualism would also be associated with lower CSF totaltau and lower prevalence of preclinical Alzheimer's disease. In relation with the noradrenergic system mentioned previously, bilingualism would induce a sustained activation of this system, explaining the beneficial effects on cognitive functions. Moreover, next to cognitive reserve, bilingualism/multilingualism would also modify the cerebral reserve, typically the thickness of several white matter fascicles or even cortical regions, such as the anterior cingulate cortex. Overall, according to studies, daily bilingual experience mitigates the typical effects of aging on cognitive functions at both, behavioral and neural levels. As mentioned in Supplementary table, education has a significant role to maintain the cognitive level during aging. Indeed, working memory, several executive functions, and visuoconstructive abilities are modulated by education (see [150]) by modulating several cognitive reserves for these functions. Some other competencies (fluency, divided attention, interference, spatial reasoning) do not seem to be correlated to education.

As indicated in the same table (column "Physical activity and other factors"), other AMF seem to be closely related to cognition during aging, such as sleep and microbiota. Indeed, poor sleep would be associated with reduced cognitive flexibility and altered microbiome composition in older adults. Altered composition of the gut microbiome may be a mechanism linking inadequate sleep to low cognitive abilities in older adults. In addition, a cognitively enriched environment that may be achieved through education may be associated with right-lateralized fronto-parietal networks, which in turn contributes to the preservation of cognitive function in aging by offsetting the age-related decline in the ability to ignore salient distraction, as mentioned by Shalev et al. [169]. Indeed, as the authors explain, the ability to suppress distractors with age is driven by the right lateralization of neural substrates (including the fronto-parietal attention network, with a key role in cognitive reserve. Physical fitness and physical activity in general are factors frequently studied as having a positive effect on electrical brain activity and cognitive functions. Their influence is manifested either through direct modulation of executive functions, by reduced obesity or even by modulating the level of choline in the brain and allowing the synthesis of neurotransmitters, or by modulating the effect of APOE- 4 . An interesting 27-year longitudinal study [145] explored the effect of regular physical activity on cognition. The authors showed a significant beneficial effect on global cognitive function in older adults that would be gender-independent, not affected by differences in survival or by potential lifestyle confounders.

As mentioned previously, these factors do not act in isolation, but are rather interrelated. Papenberg et al. [136] suggest that the gene-environment correlation is particularly important and a specific genotype can be more frequently associated with a particular environment. This could explain why individuals with an advantageous genetic profile tend to seek for a more stimulating environment. In turn, a stimulating environment enhances the expression of particular genes. In line with this, Bartrés-Faz \& Arenaza-Urquijo [12] hypothesized that the exposure to a protective and stimulating environment associated with a genetic predisposition can provide a high potential for adaptive neuroplasticity, in terms of reserve and neural compensation. A systematic review by Ngandu et al. [132] suggested that cognitive decline in seniors at risk of pathological aging can be avoided by a multi-domain intervention which involves diet, exercise, cognitive training, and vascular risk monitoring. The 2020 Lancet Commission report [110] completed a list of modifiable risk factors of pathological aging including excessive alcohol consumption, head injury, air pollution, less education, hypertension, hearing impairment, smoking, obesity, depression, physical inactivity, diabetes, and infrequent social contact. According to this report, about $40 \%$ of neurodegenerative disorders could be delayed or even prevented if a global care plan based on these factors was deployed in older adults while they are healthy. Finally, in a recent study, Belleville et al. [16] have shown in the StayFitLonger study that a multi-domain training that includes physical and cognitive activities 
may improve physical and cognitive health in older adults.

\section{LARA model: Lexical Access and Retrieval in successful Aging}

One way to synthesize and conceptualize how aging affects lexical production and cognition in general is through a neurocognitive model that integrates possible mechanisms underlying lexical difficulties in aging. We propose a comprehensive model, LARA, for Lexical Access and Retrieval in Aging. LARA describes the strategies and mechanisms gradually put in place during aging to perform lexical access and retrieval (see Figs. 1, 2 and Table 1).

An integrative view of compensatory mechanisms is also represented by the Scaffolding Theory of Aging and Cognition (STAC; [138]), based on compensatory scaffolding. According to STAC, additional networks are recruited in older adults, in interaction with defective or less-functioning ones, to maintain correct normal functioning. STAC assumes that a large cognitive reserve could determine the quality, quantity, and efficiency of compensatory scaffolding [138]. A revised version of the STAC model (STAC-r) was proposed [147] to incorporate the role of lifestyle factors that could increase or deplete brain resources and cognitive reserve. The LARA model is in line with these assumptions and our model can be seen as one of STAC-like models.

As concerns Lifespan and Reserve components (L-R), the mechanisms developed can be mostly L- or R-related, even if they may intersect. For instance, L-related strategies may be implemented to overcome increased latencies observed initially, related to the universal effect of aging during lexical production. They are mostly semantic strategies expressed either by (a) supplementary recruitment of lexico-semantic representations and increased activity of temporo-parietal regions [18] along the anterior (frontal)-posterior (lateral temporo-parietal) axis [82] or (b) a supplementary access to stored knowledge and semantic memory [26] triggered by top-down activation from frontal to medial temporal areas including hippocampi [84]. In line with this account, Catheline et al. [30] reported a significant correlation between task performance (verbal fluency) and hippocampal volume in older adults. The hippocampus has indeed an important role in semantic memory, allowing flexible maintaining and updating of semantic representations [47, 98]. On the other hand, R-related strategies can explain inter-individual variability in cognitive aging, since older adults are cognitively more or less successful depending on the amount of their reserve. For instance, during lexical production, lower-performing older adults, who display reduced accuracy and increased response latencies compared to younger adults, might not be able to rely only on semantic (L) strategies described above and additional (R) compensatory mechanisms need to be recruited. A compensatory mechanism for overcoming this difficulty could be achieved through a stronger connectivity between the left inferior frontal and left superior temporal gyri involved in phonological processing.

Therefore, we propose that in order to overcome lexical production difficulties, older adults universally implement semantic (L) strategies, and depending on their individual capacity to produce words, they might need to employ supplementary phonological (R) strategies.

The L-R compensatory strategies could be also described in terms of intrinsic TF (task-free) brain activity and various resting-state networks. This dimension, in interaction with TI (task-induced) activity, should also be considered in order to explain the cognitive evolution of adults as they age. As mentioned previously, the universal dimension of aging implies a specific pattern with reduced intra-network segregation and increased inter-network interaction, either between DMN network and executive-control and language networks [127] or between intrinsic networks such as DMN, FPN, and visual networks [77]. According to the authors, these changes occurring within and between intrinsic networks in interaction with extrinsic ones reflect agerelated adaptive dedifferentiation or reduced specificity, and compensation mechanisms. They are in line with observations reporting increased between-network and reduced within-network connectivity [29, 31, 95]. Besides these general considerations on TF changes during aging, some of the results could be related to a specific strategy. For instance, in support of a semantic strategy, Krieger-Redwood et al. [100] showed increased intrinsic connectivity between the anterior temporal lobe and the medial prefrontal cortex, within the DMN. This 


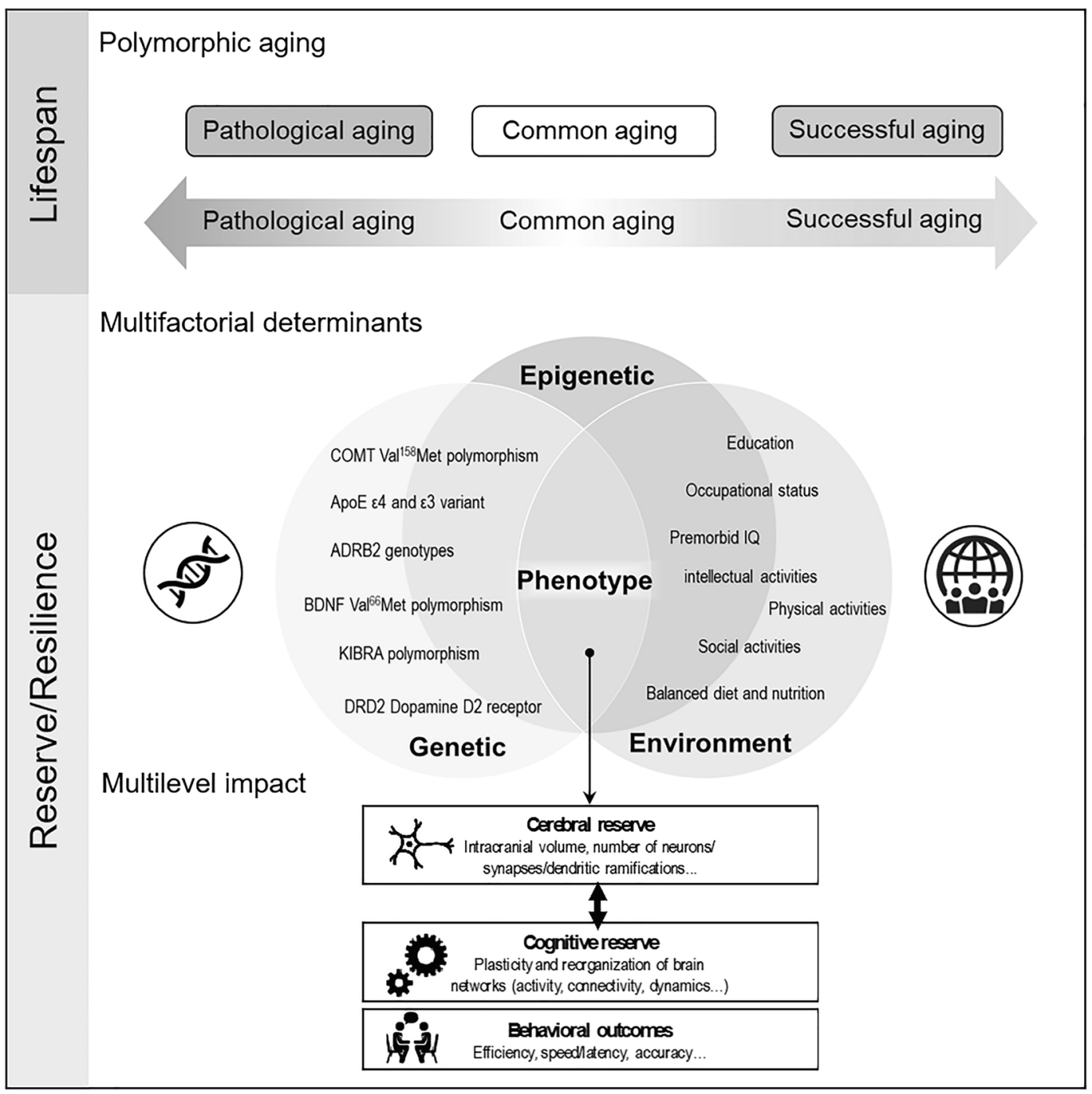

Fig. 1 Complex mechanisms associated with aging. Aging is polymorphic and three general forms of aging are described: pathological/problematic, common/usual, and successful aging. Although classically considered to be categorical, these forms of aging can also be seen as a continuum (spectrum of aging; e.g., [59]). The underlying determinants of these different forms of aging are multifactorial and depend on various genetic, environmental, and epigenetic factors (see text for a description). Concerning the "gene-environment correlation" in aging, specific genotypes are more frequently associated with a particular environment and individuals with an advantageous genetic profile seek

increased within-DMN connectivity may reflect stronger access to conceptual and semantic representation, as accounted by the semantic strategy.

The main assumption within the language-specific-domain general (LS-DG) perspective is that word production difficulties observed in the elderly involve mechanisms and compensatory strategies which include both stimulating environments. Reciprocally, stimulating environments enhance the expression of favorable genetic profiles along with epigenetic mechanisms [136]. These different factors have an impact on the phenotypic profile of individuals and, as concerns the neurocognitive phenotype, at several levels of brain structure and function. More precisely, these modulating factors influence the capacities of neural (cerebral) and cognitive reserves (agingmodulatory reserve factors, AMF). These two forms of interrelated reserves are directly related to behavioral performances such as in lexical access and retrieval, particularly affected in aging

language-specific and domain-general processes, mostly executive functions depending on prefrontal cortices. As reported above, a large panel of TI studies [21, 125, 146] and TF studies [5, 38, 50, 69, 154, 202, 209] revealed various reorganization patterns at a prefrontal level, with a tendency toward reduction of hemispheric asymmetry. As we mentioned above, naming latencies in older adults were 


\section{LARA model (Lexical Access and Retrieval in Aging)}

Language Specific (LS) compensatory mechanisms

General trend

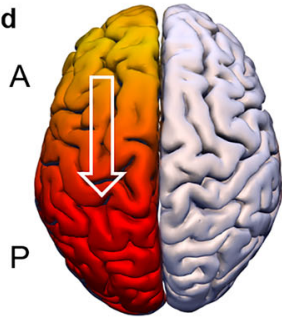

Specific features

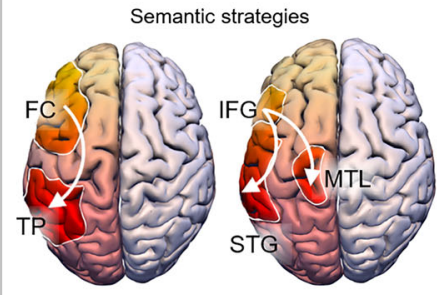

O Lifespan (L)

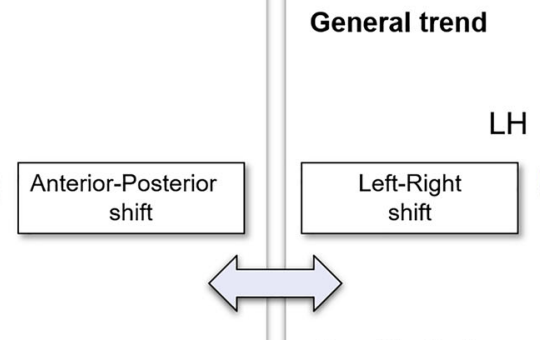

Specific features

$\mathrm{H}$
Domain General (DG) compensatory mechanisms

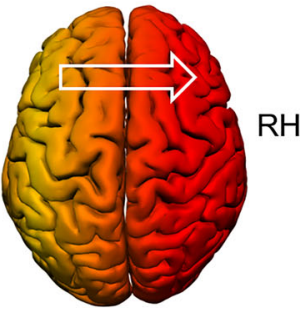

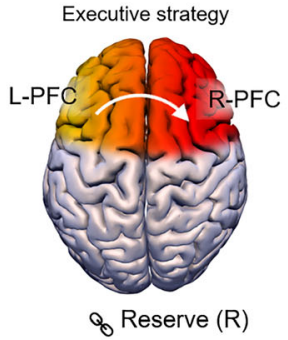

Fig. 2 LARA model (Lexical Access and Retrieval in Aging). Neurocognitive compensatory strategies associated with successful Lexical Access and Retrieval in Aging. LARA model postulates the existence of two interrelated strategies: language-specific and domain-general (LS-DG). Language-specific mechanisms imply as a general trend a shift in recruitment from the frontal regions to posterior areas. Two main strategies are typically observed. (1) Semantic strategies that are related to universal aging (lifespan aspects) and implying an over-recruitment of temporo-parietal and mesial temporal regions. More specifically, this is characterized by (i) an increased lexico-semantic representation related to supplementary activation of temporo-parietal regions; (ii) an increased access to semantic memory knowledge store engaging top-down from inferior frontal medial temporal cortices; and (iii) an increased within-DMN connectivity with stronger access to conceptual and semantic representation. (2) A phonological strategy, dependent on cognitive reserve capacity, is characterized by (i) increased connectivity between the left inferior frontal and left superior temporal gyrus to overcome phonological deficits in aging. Domain-general mechanisms generally involve recruitment from the contralateral hemisphere (traditionally the right hemisphere in the case of language). This bilateral recruitment is observed in particular in the (pre)frontal regions (executive

modulated by the degree of inter-hemispheric asymmetry of frontal regions, with shorter naming latencies being correlated with more bilateral activity in frontal regions, revealing a compensatory mechanism via executive strategies) and will also depend on the cognitive reserve (see text for more details). $A$, anterior; $P$, posterior; $F C$, frontal cortex; $T P$, temporo-parietal regions; $I F G$, inferior frontal gyrus; $S T G$, superior temporal gyrus; $M T L$, mesial temporal lobe; $L H$, left hemisphere; $R H$, right hemisphere; $L-P F C$, left prefrontal cortex; $R$ $P F C$, right prefrontal cortex. There are three main aspects of the LARA model. First of all, it considers two dynamics: (a) a universal or uniform one that refers to the general effect of age on cognition during lifespan and (b) an idiosyncratic or nonuniform one that refers to cognitive aging variability among individuals, depending on the amount of reserve or cognitive resilience of each individual. Secondly, these two dynamics are tightly and dynamically interrelated. They intervene in parallel and at any moment of aging and prompt the development of compensatory mechanisms. These mechanisms are implemented at a cognitive and cerebral level. Thirdly, LARA differentiates between two categories of compensatory mechanisms, language-specific and domain-general. To summarize these three accounts, LARA elements can be presented along two perspectives: (i) Lifespan vs. Reserve (L-R) mechanisms and (ii) Language-Specific vs. Domain-General (LS-DG) mechanisms, both types presenting interactions either within-side (L and R; LS and $\mathrm{DG}$ ) or between-sides (L-R and LS-DG)

functions, a result that is also supported by the HAROLD model [28]. These findings suggest that domain-general executive strategies are also recruited in older adults, to help maintain processing speed and improve reaction 
times. Specifically, left frontal cortices might be involved in translating affective drive states into a coordinated plan to help retrieve semantic information from memory [17].

In the column "LARA-based mechanisms" from Table 1, we interpreted the results of studies we synthesized from the last 20 years on lexical production and aging, according to mechanisms possibly involved according to our proposed LARA model. Among the 46 studies cited in Table 1, all except one can be interpreted according to LARA mechanisms. Results of the majority of studies are in line with language-specific mechanisms only (20/46) while a few $(5 / 46)$ with domain-general mechanisms. The majority of studies (21/46) reported results that could be in line with both, domain-general and language-specific mechanisms. Furthermore, more than a half $(25 / 46)$ of studies can be interpreted according to both lifespan and reserve mechanisms. Overall, our interpretation within the framework of LARA mechanisms shows that cognitive aging of lexical production is a multidimensional phenomenon that should be explored along at least two dimensions, lifespan and idiosyncratic. Even if our approach is only semiquantitative and our interpretation may be more or less subjective, results reported by these studies show a large variety of possible mechanisms explaining the ability of each individual to cope with aging effects, according to his/her own life trajectory and his/her level of cerebral, neural, and cognitive reserve. We also mentioned in Supplementary Table the main AMF that modulate the cognitive and cerebral reserve and claim that they are multidimensional and their effects are interconnected. It is difficult to disentangle, in the same individual, the effect of this or that specific factor. We rather propose that for each individual, we can depict a composite reserve index representing a group of interrelated factors, some of them being beneficial and some others deleterious for the cognitive evolution while aging. This composite reserve index clearly depends on the specific life and health trajectory of an individual, its education in a grad sense, style, and quality of life.

\section{Conclusions}

Cognitive aging is an inevitable process which affects all individuals. An important amount of studies has been conducted to assess the effect of age on cognitive functioning and to determine cognitive, behavioral, and anatomo-functional correlates and biomarkers of this process. A specific cognitive function addressed in this review was lexical production, which is generally impaired in normal aging. We showed that the decline in lexical production skills is variable among older adults, according to the variable amount of reserve. Older adults implement a variety of compensatory strategies to maintain lexical performance as long as possible and avoid pathological aging. The LARA model provides an overview of compensatory strategies and the way in which they are implemented in older adults, in terms of cognitive mechanisms and cerebral networks. These strategies relate both to languagespecific mechanisms and to domain-general, executive functions. We argue that the degree and variability of cognitive aging depend on the amount of reserve specific to each individual and that they are modulated by a large panel of AMF factors. A variety of mechanisms and compensatory strategies coexist in the same individual to compensate for complex deleterious effects of aging, LARA describing only some of them. A better understanding of these strategies and of the protective and risk factors for pathological aging is critical to society and public policies, to promote successful aging and avoid or push back the occurrence of neurodegenerative disorders.

In conclusion and as mentioned in Sholl and Rattant [163], aging is one of the most challenging public health issues, considered as a "cellular danger response to environmental stressors or injury leading to the development of neurodegenerative disorders." New research directions have recently emerged to understand the effect of genetic, biological, social, and environmental factors on cognitive reserve in each individual. The role of life conditions, environment, physical activities, or nutrition seems to be also significantly considered. Identifying personalized biomarkers of the cognitive reserve can help characterizing biologically vulnerable individuals and the implementation of strategies that may help neurobiological changes at a cerebral level, reflected for instance, by increased brain connectivity and new circuits and strategies to overcome cognitive weaknesses. Overall, these new research directions will help elucidating the role of beneficial AMF factors in promoting a successful aging.

Supplementary Information The online version contains supplementary material available at https://doi.org/10.1007/s11357021-00367-5.

Funding This work has been funded by NeuroCoG IDEX UGA in the framework of the "Investissements d'avenir" program [grant number ANR-15-IDEX-02]. 
Open Access This article is licensed under a Creative Commons Attribution 4.0 International License, which permits use, sharing, adaptation, distribution and reproduction in any medium or format, as long as you give appropriate credit to the original author(s) and the source, provide a link to the Creative Commons licence, and indicate if changes were made. The images or other third party material in this article are included in the article's Creative Commons licence, unless indicated otherwise in a credit line to the material. If material is not included in the article's Creative Commons licence and your intended use is not permitted by statutory regulation or exceeds the permitted use, you will need to obtain permission directly from the copyright holder. To view a copy of this licence, visit http://creativecommons.org/licenses/by/4.0/.

\section{References}

1. Abrams L, Farrell MT. Language processing in normal aging. In: Guendouzi J, Loncke F, Williams MJ, editors. The handbook of psycholinguistic and cognitive processes: Routledge; 2011. https://doi.org/10.4324/9780203848005. ch3.

2. Abrams L, Trunk DL, Margolin SJ. Resolving tip-of-thetongue states in young and older adults: the role of phonology. Aging and the elderly: psychology, sociology, and health. 2007:1-41.

3. Albert SM, Gurland B, Maestre G, Jacobs DM, Stern Y, Mayeux R. APOE genotype influences functional status among elderly without dementia. Am J Med Genet. 1995;60(6):583-7. https://doi.org/10.1002 /ajmg.1320600621.

4. Andrews-Hanna JR, Reidler JS, Sepulcre J, Poulin R, Buckner RL. Functional-anatomic fractionation of the brain's default network. Neuron. 2010;65(4):550-62. https://doi.org/10.1016/j.neuron.2010.02.005.

5. Andrews-Hanna JR, Snyder AZ, Vincent JL, Lustig C, Head D, Raichle ME, et al. Disruption of large-scale brain systems in advanced aging. Neuron. 2007;56(5):924-35. https://doi.org/10.1016/j.neuron.2007.10.038.

6. Anstey KJ, Lipnicki DM, Low L-F. Cholesterol as a risk factor for dementia and cognitive decline: a systematic review of prospective studies with meta-analysis. Am J Geriatr Psychiatry. 2008;16(5):343-54. https://doi. org/10.1097/01.JGP.0000310778.20870.ae.

7. Anstey KJ, von Sanden C, Salim A, O'Kearney R. Smoking as a risk factor for dementia and cognitive decline: a meta-analysis of prospective studies. Am J Epidemiol. 2007;166(4):367-78. https://doi.org/10.1093 /aje/kwm116.

8. Antoniou M, Wright SM. Uncovering the mechanisms responsible for why language learning may promote healthy cognitive aging. Front Psychol. 2017;8:2217. https://doi.org/10.3389/fpsyg.2017.02217.

9. Astell AJ, Harley TA. Tip-of-the-tongue states and lexical access in dementia. Brain Lang. 1996;54(2):196-215. https://doi.org/10.1006/brln.1996.0071.

10. Balduino E, de Melo BAR, de Sousa Mota da Silva, L., Martinelli, J. E., \& Cecato, J. F. The "SuperAgers" construct in clinical practice: neuropsychological assessment of illiterate and educated elderly. Int Psychogeriatr. 2020;32(2):191-8. https://doi.org/10.1017 /S1041610219001364.

11. Balota DA, Dolan PO, Duchek JM. Memory changes in healthy order adults. In: Tulving E, Craik FIM, editors. Oxford Handbook of Memory: Oxford University Press; 2000. p. 395-403.

12. Bartrés-Faz D, Arenaza-Urquijo EM. Structural and functional imaging correlates of cognitive and brain reserve hypotheses in healthy and pathological aging. Brain Topogr. 2011;24(3-4):340-57. https://doi.org/10.1007 /s10548-011-0195-9.

13. Barulli D, Stern Y. Efficiency, capacity, compensation, maintenance, plasticity: emerging concepts in cognitive reserve. Trends Cogn Sci. 2013;17(10):502-9. https://doi. org/10.1016/j.tics.2013.08.012.

14. Bassuk SS, Glass TA, Berkman LF. Social disengagement and incident cognitive decline in community-dwelling elderly persons. Ann Intern Med. 1999;131(3):165-73. https://doi.org/10.7326/0003-4819-131-3-19990803000002.

15. Bastin C, Yakushev I, Bahri MA, Fellgiebel A, Eustache F, Landeau B, et al. Cognitive reserve impacts on interindividual variability in resting-state cerebral metabolism in normal aging. NeuroImage. 2012;63(2):713-22. https://doi.org/10.1016/j.neuroimage.2012.06.074.

16. Belleville S, Cuesta M, Bieler-Aeschlimann M, Giacomino K, Widmer A, Mittaz Hager AG, et al. Rationale and protocol of the StayFitLonger study: a multicentre trial to measure efficacy and adherence of a home-based computerised multidomain intervention in healthy older adults. BMC Geriatr. 2020;20(1):315. https://doi. org/10.1186/s12877-020-01709-2.

17. Binder JR, Desai RH. The neurobiology of semantic memory. Trends Cogn Sci. 2011;15(11):527-36. https://doi. org/10.1016/j.tics.2011.10.001.

18. Binder JR, Desai RH, Graves WW, Conant LL. Where is the semantic system? A critical review and meta-analysis of 120 functional neuroimaging studies. Cereb Cortex. 2009;19(12):2767-96. https://doi.org/10.1093 /cercor/bhp055.

19. Binder JR, Frost JA, Hammeke TA, Bellgowan PS, Rao $\mathrm{SM}, \mathrm{Cox} \mathrm{RW}$. Conceptual processing during the conscious resting state. A functional MRI study. J Cogn Neurosci. 1999;11(1):80-95.

20. Böger A, Huxhold O. Do the antecedents and consequences of loneliness change from middle adulthood into old age? Dev Psychol. 2018;54(1):181-97. https://doi. org/10.1037/dev0000453.

21. Bosch B, Bartrés-Faz D, Rami L, Arenaza-Urquijo EM, Fernández-Espejo $\mathrm{D}$, Junqué $\mathrm{C}$, et al. Cognitive reserve modulates task-induced activations and deactivations in healthy elders, amnestic mild cognitive impairment and mild Alzheimer's disease. Cortex. 2010;46(4):451-61. https://doi.org/10.1016/j.cortex.2009.05.006.

22. Boudiaf N, Laboissière R, Cousin É, Fournet N, Krainik A, Baciu M. Behavioral evidence for a differential modulation of semantic processing and lexical production by aging: a full linear mixed-effects modeling approach. Aging Neuropsychol Cogn. 2018;25(1):1-22. https://doi. org/10.1080/13825585.2016.1257100. 
23. Braver TS, West R. Working memory, executive control, and aging. In: Craik FIM, Salthouse TA, editors. The handbook of aging and cognition: Psychology Press; 2008. p. 311-72.

24. Bretsky P, Guralnik JM, Launer L, Albert M, Seeman TE. The role of APOE-epsilon4 in longitudinal cognitive decline: MacArthur studies of successful aging. Neurology. 2003;60(7):1077-81. https://doi.org/10.1212/01. WNL.0000055875.26908.24.

25. Burke DM, Mackay DG. Memory, language, and ageing. Philosophical Transactions of the Royal Society of London. Series B: Biological Sciences. 1997;352(1363): 1845-56. https://doi.org/10.1098/rstb.1997.0170.

26. Burke DM, MacKay DG, Worthley JS, Wade E. On the tip of the tongue: what causes word finding failures in young and older adults? J Mem Lang. 1991;30(5):542-79. https://doi.org/10.1016/0749-596X(91)90026-G.

27. Burke DM, Shafto MA. Language and aging. In: Craik FIM, Salthouse TA, editors. The handbook of aging and cognition: Psychology Press; 2008. p. 373-443.

28. Cabeza R. Hemispheric asymmetry reduction in older adults: the HAROLD model. Psychol Aging. 2002;17(1): 85-100. https://doi.org/10.1037//0882-7974.17.1.85.

29. Cao M, Wang J-H, Dai Z-J, Cao X-Y, Jiang L-L, Fan F-M, et al. Topological organization of the human brain functional connectome across the lifespan. Developmental Cognitive Neuroscience. 2014;7:76-93. https://doi. org/10.1016/j.den.2013.11.004.

30. Catheline G, Amieva H, Dilharreguy B, Bernard C, Duperron $\mathrm{M}-\mathrm{G}$, Helmer C, et al. Semantic retrieval over time in the aging brain: structural evidence of hippocampal contribution. Hippocampus. 2015;25(9):1008-16. https://doi.org/10.1002/hipo.22423.

31. Chen Q, Xia Y, Zhuang K, Wu X, Liu G, Qiu J. Decreased inter-hemispheric interactions but increased intrahemispheric integration during typical aging. Aging. 2019;11(22):10100-15. https://doi.org/10.18632 /aging.102421.

32. Christensen H, Mackinnon AJ, Korten AE, Jorm AF, Henderson AS, Jacomb P, et al. An analysis of diversity in the cognitive performance of elderly community dwellers: individual differences in change scores as a function of age. Psychol Aging. 1999;14(3):365-79. https://doi. org/10.1037/0882-7974.14.3.365.

33. Collette F, Salmon E. Fonctionnement exécutif et réseaux cérébraux. Rev Neuropsychol. 2014;6(4):256-66. https://doi.org/10.1684/nrp.2014.0321.

34. Condret-Santi V, Barbeau EJ, Matharan F, Le Goff M, Dartigues J-F, Amieva H. Prevalence of word retrieval complaint and prediction of dementia in a populationbased study of elderly subjects. Dement Geriatr Cogn Disord. 2013;35(5-6):313-24. https://doi.org/10.1159 /000342594.

35. Connor LT, Spiro A, Obler LK, Albert ML. Change in object naming ability during adulthood. J Gerontol Ser B Psychol Sci Soc Sci. 2004;59(5):P203-9. https://doi. org/10.1093/geronb/59.5.P203.

36. Cosco TD, Prina AM, Perales J, Stephan BCM, Brayne C. Operational definitions of successful aging: a systematic review. Int Psychogeriatr. 2014;26(3):373-81. https://doi. org/10.1017/S1041610213002287.
37. Croezen S, Avendano M, Burdorf A, van Lenthe FJ. Social participation and depression in old age: a fixed-effects analysis in 10 European countries. Am J Epidemiol. 2015;182(2):168-76. https://doi.org/10.1093/aje/kwv015.

38. Damoiseaux JS, Beckmann CF, Arigita EJS, Barkhof F, Scheltens P, Stam CJ, et al. Reduced resting-state brain activity in the "default network" in normal aging. Cereb Cortex. 2008;18(8):1856-64. https://doi.org/10.1093 /cercor/bhm 207.

39. Davis SW, Dennis NA, Daselaar SM, Fleck MS, Cabeza R. Qué PASA? The posterior-anterior shift in aging. Cereb Cortex. 2008;18(5):1201-9. https://doi.org/10.1093 /cercor/bhm155.

40. Deary IJ, Allerhand M, Der G. Smarter in middle age, faster in old age: a cross-lagged panel analysis of reaction time and cognitive ability over 13 years in the West of Scotland Twenty-07 Study. Psychol Aging. 2009;24(1): 40-7. https://doi.org/10.1037/a0014442.

41. Dell GS. A spreading-activation theory of retrieval in sentence production. Psychol Rev. 1986;93(3):283-321. https://doi.org/10.1037/0033-295X.93.3.283.

42. Dennis NA, Cabeza R. Neuroimaging of healthy cognitive aging. In: Craik FIM, Salthouse TA, editors. The handbook of aging and cognition: Psychology Press; 2008. p. 1-54.

43. Diaz MT, Rizio AA, Zhuang J. The neural language systems that support healthy aging: integrating function, structure, and behavior. Lang Ling Compass. 2016;10(7):314 34. https://doi.org/10.1111/lnc3.12199.

44. Dik MG, Jonker C, Comijs HC, Bouter LM, Twisk JWR, van Kamp GJ, et al. Memory complaints and APOEepsilon 4 accelerate cognitive decline in cognitively normal elderly. Neurology. 2001;57(12):2217-22. https://doi. org/10.1212/WNL.57.12.2217.

45. Dorot $\mathrm{D}$, Mathey $\mathrm{S}$. Accès aux représentations sémantiques et phonologiques chez des adultes jeunes et âgés: Une étude des mots sur le bout de la langue. Psychol Fr. 2013;58(1):1-16. https://doi.org/10.1016/j. psfr.2012.06.002.

46. Duarte LR, Robert C. Semantic richness influences naming pictures in old age and in Alzheimer's disease. J Neurolinguistics. 2014;31:55-68. https://doi.org/10.1016 /j.jneuroling.2014.06.004.

47. Duff MC, Covington NV, Hilverman C, Cohen NJ. Semantic memory and the hippocampus: revisiting, reaffirming, and extending the reach of their critical relationship. Front Hum Neurosci. 2020;13:471. https://doi. org/10.3389/fnhum.2019.00471.

48. Egan MF, Goldberg TE, Kolachana BS, Callicott JH, Mazzanti CM, Straub RE, et al. Effect of COMT Val108/ 158 Met genotype on frontal lobe function and risk for schizophrenia. Proc Natl Acad Sci. 2001;98(12):6917-22. https://doi.org/10.1073/pnas.111134598.

49. Egan MF, Kojima M, Callicott JH, Goldberg TE, Kolachana BS, Bertolino A, et al. The BDNF val66met polymorphism affects activity-dependent secretion of BDNF and human memory and hippocampal function. Cell. 2003;112(2):257-69. https://doi.org/10.1016 /S0092-8674(03)00035-7.

50. Esposito F, Aragri A, Pesaresi I, Cirillo S, Tedeschi G, Marciano E, et al. Independent component model of the default-mode brain function: combining individual-level 
and population-level analyses in resting-state fMRI. Magn Reson Imaging. 2008;26(7):905-13. https://doi. org/10.1016/j.mri.2008.01.045.

51. Evrard M. Ageing and lexical access to common and proper names in picture naming. Brain Lang. 2002;81(13):174-9. https://doi.org/10.1006/brln.2001.2515.

52. Eyme KM, Domin M, Gerlach FH, Hosten N, Schmidt CO, Gaser C, et al. Physically active life style is associated with increased grey matter brain volume in a medial parietofrontal network. Behav Brain Res. 2019;359:215-22. https://doi.org/10.1016/j.bbr.2018.10.042.

53. Facal D, Juncos-Rabadán O, Rodríguez MS, Pereiro AX. Tip-of-the-tongue in aging: influence of vocabulary, working memory and processing speed. Aging Clin Exp Res. 2012;24(6). https://doi.org/10.3275/8586.

54. Féart C, Samieri C, Barberger-Gateau P. Mediterranean diet and cognitive function in older adults. Current Opinion in Clinical Nutrition and Metabolic Care. 2010;13(1):14-8. https://doi.org/10.1097/MCO.0b013 e3283331fe4.

55. Fechner HB, Pachur T, Schooler LJ. How does aging impact decision making? The contribution of cognitive decline and strategic compensation revealed in a cognitive architecture. J Exp Psychol Learn Mem Cogn. 2019;45(9): 1634-63. https://doi.org/10.1037/xlm0000661.

56. Ferry M. Bases nutritionnelles pour un vieillissement réussi. Cahiers de Nutrition et de Diététique. 2008;43(2): 90-6. https://doi.org/10.1016/S0007-9960(08)71427-5.

57. Flanagan EW, Most J, Mey JT, Redman LM. Calorie restriction and aging in humans. Annu Rev Nutr. 2020;40(1):105-33. https://doi.org/10.1146/annurev-nutr122319-034601.

58. Fornito A, Zalesky A, Breakspear M. The connectomics of brain disorders. Nat Rev Neurosci. 2015;16(3):159-72. https://doi.org/10.1038/nrn3901.

59. Franceschi C, Garagnani P, Morsiani C, Conte M, Santoro A, Grignolio A, et al. The continuum of aging and agerelated diseases: common mechanisms but different rates. Frontiers in Medicine. 2018;5:61. https://doi.org/10.3389 /fmed.2018.00061.

60. Fratiglioni L, Paillard-Borg S, Winblad B. An active and socially integrated lifestyle in late life might protect against dementia. The Lancet Neurology. 2004;3(6):343-53. https://doi.org/10.1016/S1474-4422(04)00767-7.

61. Friedmann N, Biran M, Dotan D. Lexical retrieval and its breakdown in aphasia and developmental language impairment. In: Boeckx C, Grohmann KK, editors. The Cambridge Handbook of Biolinguistics: Cambridge University Press; 2013. p. 350-74. http://ebooks. cambridge.org/ref/id/CBO9780511980435A030.

62. Galinsky AD, Ku G, Wang CS. Perspective-taking and selfother overlap: fostering social bonds and facilitating social coordination. Group Processes \& Intergroup Relations. 2005;8(2):109-24. https://doi.org/10.1177 $/ 1368430205051060$.

63. Geerligs L, Renken RJ, Saliasi E, Maurits NM, Lorist MM. A brain-wide study of age-related changes in functional connectivity. Cereb Cortex. 2015;25(7):1987-99. https://doi.org/10.1093/cercor/bhu012.

64. Geerligs L, Saliasi E, Maurits NM, Renken RJ, Lorist MM. Brain mechanisms underlying the effects of aging on different aspects of selective attention. NeuroImage. 2014;91:52-62. https://doi.org/10.1016/j. neuroimage.2014.01.029.

65. Getzmann S, Gajewski PD, Hengstler JG, Falkenstein M, Beste C. BDNF Val66Met polymorphism and goaldirected behavior in healthy elderly - evidence from auditory distraction. NeuroImage. 2013;64:290-8. https://doi. org/10.1016/j.neuroimage.2012.08.079.

66. Glisky E. Changes in cognitive function in human aging. In: Riddle D, editor. Brain aging: models, methods, and mechanisms, vol. 20072731: CRC Press/Routledge/Taylor \& Francis Group; 2007. p. 3-20. https://doi.org/10.1201 /9781420005523.sec1.

67. Gordon JK, Kurczek JC. The ageing neighbourhood: phonological density in naming. Language, Cognition and Neuroscience. 2014;29(3):326-44. https://doi.org/10.1080 /01690965.2013.837495.

68. Goulet P, Ska B, Kahn HJ. Is there a decline in picture naming with advancing age? J Speech Hear Res. 1994;37(3):629-44. https://doi.org/10.1044/jshr.3703.629.

69. Grady CL, Protzner AB, Kovacevic N, Strother SC, AfshinPour B, Wojtowicz M, et al. A multivariate analysis of agerelated differences in default mode and task-positive networks across multiple cognitive domains. Cereb Cortex. 2010;20(6): 1432-47. https://doi.org/10.1093/cercor/bhp207.

70. Grady CL, Sarraf S, Saverino C, Campbell K. Age differences in the functional interactions among the default, frontoparietal control, and dorsal attention networks. Neurobiol Aging. 2016;41:159-72. https://doi. org/10.1016/j.neurobiolaging.2016.02.020.

71. Grandchamp R, Rapin L, Perrone-Bertolotti M, Pichat C, Haldin C, Cousin E, et al. The ConDialInt model: condensation, dialogality, and intentionality dimensions of inner speech within a hierarchical predictive control framework. Front Psychol. 2019;10:30. https://doi.org/10.3389 /fpsyg.2019.02019.

72. Gusnard DA, Akbudak E, Shulman GL, Raichle ME. Medial prefrontal cortex and self-referential mental activity: relation to a default mode of brain function. Proc Natl Acad Sci. 2001;98(7):4259-64. https://doi.org/10.1073 /pnas.071043098.

73. Harada CN, Natelson Love MC, Triebel KL. Normal cognitive aging. Clin Geriatr Med. 2013;29(4):737-52. https://doi.org/10.1016/j.cger.2013.07.002.

74. Hartshorne JK, Germine LT. When does cognitive functioning peak? The asynchronous rise and fall of different cognitive abilities across the lifespan. Psychol Sci. 2015;26(4):433-43. https://doi.org/10.1177 /0956797614567339.

75. Hasher L, Lustig C, Zacks R. Inhibitory mechanisms and the control of attention. In: Conway A, Jarrold C, Kane M, Miyake A, Towse J, editors. Variation in working memory: Oxford University Press; 2008. p. 227-49. https://doi. org/10.1093/acprof:oso/9780195168648.003.0009.

76. Hasher L, Zacks RT. Working memory, comprehension, and aging: a review and a new view. In: Bower GH, editor. Psychology of learning and motivation, vol. 22: Elsevier; 1988. p. 193-225. https://doi.org/10.1016/S0079-7421(08 60041-9.

77. He L, Wang X, Zhuang K, Qiu J. Decreased dynamic segregation but increased dynamic integration of the 
resting-state functional networks during normal aging. Neuroscience. 2020;437:54-63. https://doi.org/10.1016/j. neuroscience.2020.04.030.

78. He W, Goodkind D, Kowal P. An aging world: 2015: United States Census Bureau; 2016.

79. Hertzog C, Kramer AF, Wilson RS, Lindenberger U. Enrichment effects on adult cognitive development: can the functional capacity of older adults be preserved and enhanced? Psychol Sci Public Interest. 2008;9(1):1-65. https://doi.org/10.1111/j.1539-6053.2009.01034.x.

80. Hickok G, Poeppel D. The cortical organization of speech processing. Nat Rev Neurosci. 2007;8(5):393-402. https://doi.org/10.1038/nrn2113.

81. Higby E, Cahana-Amitay D, Vogel-Eyny A, Spiro A, Albert ML, Obler LK. The role of executive functions in object- and action-naming among older adults. Exp Aging Res. 2019;45(4):306-30. https://doi.org/10.1080/0361073 X.2019.1627492.

82. Hoyau E, Cousin E, Pichat C, Jaillard A, Baciu M. Left anterior-posterior aging effect for lexical production. Functional MRI assessment. Cognitive Neuroscience Society Meeting, San Francisco, USA. 2017.

83. Hoyau E, Gigleux M, Cousin É, Fournet N, Pichat C, Jaillard A, et al. Effet des activités sociales de loisirs sur la dénomination orale d'objets lors du vieillissement sain Approche multimodale. Gériatrie et Psychologie Neuropsychiatrie Du Viellissement. 2018a;16(1):96-105. https://doi.org/10.1684/pnv.2017.0715.

84. Hoyau E, Roux-Sibilon A, Boudiaf N, Pichat C, Cousin E, Krainik A, et al. Aging modulates fronto-temporal cortical interactions during lexical production. A dynamic causal modeling study. Brain Lang. 2018b;184:11-9. https://doi. org/10.1016/j.bandl.2018.06.003.

85. Indefrey P. The spatial and temporal signatures of word production components: a critical update. Front Psychol. 2011;2:255. https://doi.org/10.3389/fpsyg.2011.00255.

86. Indefrey P, Levelt WJM. The spatial and temporal signatures of word production components. Cognition. 2004;92(1-2):101-44. https://doi.org/10.1016/j. cognition.2002.06.001.

87. Irwin K, Sexton C, Daniel T, Lawlor B, Naci L. Healthy aging and dementia: two roads diverging in midlife? Front Aging Neurosci. 2018;10:275. https://doi.org/10.3389 /fnagi.2018.00275.

88. Izaute M. De la dénomination: La spécificité des noms propres. L'Année psychologique. 1999;99(4):731-51. https://doi.org/10.3406/psy.1999.28506.

89. James BD, Wilson RS, Barnes LL, Bennett DA. Late-life social activity and cognitive decline in old age. $\mathrm{J}$ Int Neuropsychol Soc. 2011;17(6):998-1005. https://doi. org/10.1017/S1355617711000531.

90. James LE, Burke DM. Phonological priming effects on word retrieval and tip-of-the-tongue experiences in young and older adults. J Exp Psychol Learn Mem Cogn. 2000;26(6):1378-91. https://doi.org/10.1037/02787393.26.6.1378.

91. Jopp DS, Park M-KS, Lehrfeld J, Paggi ME. Physical, cognitive, social and mental health in near-centenarians and centenarians living in New York City: findings from the Fordham Centenarian Study. BMC Geriatr. 2016;16(1): 1-10. https://doi.org/10.1186/s12877-015-0167-0.
92. Katzman R. Education and the prevalence of dementia and Alzheimer's disease. Neurology. 1993;43(1):13-20. https://doi.org/10.1212/WNL.43.1_Part_1.13.

93. Kauppi K, Nilsson L-G, Adolfsson R, Eriksson E, Nyberg L. KIBRA polymorphism is related to enhanced memory and elevated hippocampal processing. J Neurosci. 2011;31(40):14218-22. https://doi.org/10.1523 /JNEUROSCI.3292-11.2011.

94. Kennedy KM, Reese ED, Horn MM, Sizemore AN, Unni AK, Meerbrey ME, et al. BDNF val66met polymorphism affects aging of multiple types of memory. Brain Res. 2015;1612:104-17. https://doi.org/10.1016/j. brainres.2014.09.044.

95. King BR, van Ruitenbeek P, Leunissen I, Cuypers K, Heise K-F, Santos Monteiro T, et al. Age-related declines in motor performance are associated with decreased segregation of large-scale resting state brain networks. Cereb Cortex. 2018;28(12):4390-402. https://doi.org/10.1093 /cercor/bhx297.

96. Kirkwood TBL. Why and how are we living longer? Exp Physiol. 2017;102(9):1067-74. https://doi.org/10.1113 /EP086205.

97. Klimova B, Pikhart M. Current research on the impact of foreign language learning among healthy seniors on their cognitive functions from a positive psychology perspective A systematic review. Front Psychol. 2020;11:765. https://doi.org/10.3389/fpsyg.2020.00765.

98. Klooster NB, Duff MC. Remote semantic memory is impoverished in hippocampal amnesia. Neuropsychologia. 2015;79(Pt A):42-52. https://doi. org/10.1016/j.neuropsychologia.2015.10.017.

99. Korkki SM, Richter FR, Jeyarathnarajah P, Simons JS. Healthy ageing reduces the precision of episodic memory retrieval. Psychol Aging. 2020;35(1):124 42. https://doi. org $/ 10.1037 /$ pag0000432.

100. Krieger-Redwood K, Wang H-T, Poerio G, Martinon LM, Riby LM, Smallwood J, et al. Reduced semantic control in older adults is linked to intrinsic DMN connectivity. Neuropsychologia. 2019;132:107133. https://doi. org/10.1016/j.neuropsychologia.2019.107133.

101. LaGrone S, Spieler DH. Lexical competition and phonological encoding in young and older speakers. Psychol Aging. 2006;21(4):804-9. https://doi.org/10.1037/08827974.21.4.804.

102. Lancheros M, Jouen A-L, Laganaro M. Neural dynamics of speech and non-speech motor planning. Brain Lang. 2020;203:104742. https://doi.org/10.1016/j. bandl.2020.104742.

103. Lecouvey G, Quinette P, Kalpouzos G, Guillery-Girard B, Bejanin A, Gonneaud J, et al. Binding in working memory and frontal lobe in normal aging: is there any similarity with autism? Front Hum Neurosci. 2015;9:90. https://doi. org/10.3389/fnhum.2015.00090.

104. Lee SH, Kim H, Kim J, Yoon JH, Kim SR. Initial phase performance in a 30 -s verbal fluency task as being reflective of aging effect. Geriatr Gerontol Int. 2015;15(4):496500. https://doi.org/10.1111/ggi.12284.

105. Leist AK. Social media use of older adults: a mini-review. Gerontology. 2013;59(4):378-84. 
106. Lezak M, Howieson DB, Bigler ED, Tranel D. Neuropsychological assessment. 5th ed: Oxford University Press; 2012.

107. Li S-C, Schmiedek F, Huxhold O, Röcke C, Smith J, Lindenberger U. Working memory plasticity in old age: practice gain, transfer, and maintenance. Psychol Aging. 2008;23(4):731-42. https://doi.org/10.1037/a0014343.

108. Li Z, Moore AB, Tyner C, Hu X. Asymmetric connectivity reduction and its relationship to "HAROLD" in aging brain. Brain Res. 2009;1295:149-58. https://doi. org/10.1016/j.brainres.2009.08.004.

109. Liang X, Zou Q, He Y, Yang Y. Topologically reorganized connectivity architecture of default-mode, executive-control, and salience networks across working memory task loads. Cereb Cortex. 2016;26(4):1501-11. https://doi. org/10.1093/cercor/bhu316.

110. Livingston G, Huntley J, Sommerlad A, Ames D, Ballard $\mathrm{C}$, Banerjee S, et al. Dementia prevention, intervention, and care: 2020 report of the Lancet Commission. Lancet. 2020;396(10248):413-46. https://doi.org/10.1016/S01406736(20)30367-6.

111. Loevenbruck H, Grandchamp R, Rapin L, Nalborczyk L, Dohen M, Perrier P, et al. A cognitive neuroscience view of inner language: to predict and to hear, see, feel. In: Langland-Hassan P, Vicente A, editors. Inner Speech: New Voices: Oxford University Press; 2018. p. 131-67.

112. Luo L, Craik FI. Aging and memory: a cognitive approach. Can J Psychiatry. 2008;53(6):346-53. https://doi. org/10.1177/070674370805300603.

113. Lustig C, Hasher L, Zacks RT. Inhibitory deficit theory: recent developments in a "new view". In: Gorfein DS, MacLeod CM, editors. Inhibition in cognition: American Psychological Association; 2007. p. 145-62. https://doi. org/10.1037/11587-008.

114. MacKay DG. Temporal organization of perception and action. In The Organization of perception and action (pp. 90-110). Springer. 1987. https://doi.org/10.1007/978-14612-4754-8 5 .

115. MacKay DG, Abrams L. Age-linked declines in retrieving orthographic knowledge: Empirical, practical, and theoretical implications. Psychol Aging. 1998;13(4):647-62. https://doi.org/10.1037/0882-7974.13.4.647.

116. MacKay DG, Burke DM. Cognition and aging: a theory of new learning and the use of old connections. In: Stone FGA, West R, editors. Advances in psychology, vol. 71: North-Holland; 1990. p. 213-63. https://doi.org/10.1016 /S0166-4115(08)60159-4.

117. Malagurski B, Liem F, Oschwald J, Mérillat S, Jäncke L. Longitudinal functional brain network reconfiguration in healthy aging. Hum Brain Mapp. 2020;41(17):4829-45. https://doi.org/10.1002/hbm.25161.

118. Manenti R, Brambilla M, Petesi M, Miniussi C, Cotelli M. Compensatory networks to counteract the effects of ageing on language. Behav Brain Res. 2013;249:22-7. https://doi. org/10.1016/j.bbr.2013.04.011.

119. Marosi K, Mattson MP. BDNF mediates adaptive brain and body responses to energetic challenges. Trends Endocrinol Metab. 2014;25:89-98.

120. Martinson M, Berridge C. Successful aging and its discontents: a systematic review of the social gerontology literature. The Gerontologist. 2015;55(1):58-69. https://doi.org/10.1093/geront/gnu037.

121. Mason MF, Norton MI, Van Horn JD, Wegner DM, Grafton ST, Macrae CN. Wandering minds: the default network and stimulus-independent thought. Science. 2007;315(5810):393-5. https://doi.org/10.1126 /science.1131295.

122. Matsumoto M, Weickert CS, Beltaifa S, Kolachana B, Chen J, Hyde TM, et al. Catechol O-methyltransferase (COMT) mRNA expression in the dorsolateral prefrontal cortex of patients with schizophrenia. Neuropsychopharmacology. 2003;28(8):1521-30. https://doi.org/10.1038/sj. npp. 1300218 .

123. Mazoyer B, Zago L, Mellet E, Bricogne S, Etard O, Houdé $\mathrm{O}$, et al. Cortical networks for working memory and executive functions sustain the conscious resting state in man. Brain Res Bull. 2001;54(3):287-98. https://doi. org/10.1016/S0361-9230(00)00437-8.

124. Menec VH. The relation between everyday activities and successful aging: a 6-year longitudinal study. J Gerontol Ser B Psychol Sci Soc Sci. 2003;58(2):S74-82. https://doi. org/10.1093/geronb/58.2.S74.

125. Mevel K, Landeau B, Fouquet M, La Joie R, Villain N, Mézenge F, et al. Age effect on the default mode network, inner thoughts, and cognitive abilities. Neurobiol Aging. 2013;34(4):1292-301. https://doi.org/10.1016/j. neurobiolaging.2012.08.018.

126. Meyer AM, Federmeier KD. Event-related potentials reveal the effects of aging on meaning selection and revision. Psychophysiology. 2010;47(4):673-86. https://doi. org/10.1111/j.1469-8986.2010.00983.x.

127. Muller AM, Mérillat S, Jäncke L. Older but still fluent? Insights from the intrinsically active baseline configuration of the aging brain using a data driven graph-theoretical approach. NeuroImage. 2016;127:346-62. https://doi. org/10.1016/j.neuroimage.2015.12.027.

128. Murman D. The impact of age on cognition. Semin Hear. 2015;36(03):111-21. https://doi.org/10.1055/s-00351555115.

129. Murer MG, Yan Q, Raisman-Vozari R. Brain-derived neurotrophic factor in the control human brain, and in Alzheimer's disease and Parkinson's disease. Prog Neurobiol. 2001;63(1):71-124. https://doi.org/10.1016 /S0301-0082(00)00014-9.

130. Murphy DR, Craik FIM, Li KZH, Schneider BA. Comparing the effects of aging and background noise on short-term memory performance. Psychol Aging. 2000;15(2):323-34. https://doi.org/10.1037/08827974.15.2.323.

131. Murray BD, Anderson MC, Kensinger EA. Older adults can suppress unwanted memories when given an appropriate strategy. Psychol Aging. 2015;30(1):9-25. https://doi. org/10.1037/a0038611.

132. Ngandu T, Lehtisalo J, Solomon A, Levälahti E, Ahtiluoto $\mathrm{S}$, Antikainen R, et al. A 2 year multidomain intervention of diet, exercise, cognitive training, and vascular risk monitoring versus control to prevent cognitive decline in at-risk elderly people (FINGER): a randomised controlled trial. Lancet. 2015;385(9984):2255-63. https://doi.org/10.1016 /S0140-6736(15)60461-5. 
133. Nicholas M, Barth C, Obler LK, Au R, Albert ML. Naming in normal aging and dementia of the Alzheimer's type. In: Goodglass H, Wingfield A, editors. Anomia: Neuroanatomical and cognitive correlates: Elsevier; 1997. p. 166-88. https://doi.org/10.1016/B978-0122896859/50011-9.

134. Nyberg L, Maitland SB, Rönnlund M, Bäckman L, Dixon RA, Wahlin $\AA$, et al. Selective adult age differences in an age-invariant multifactor model of declarative memory. Psychol Aging. 2003;18(1):149-60. https://doi. org/10.1037/0882-7974.18.1.149.

135. Oh S-A, Ha J-W. The effects of aging and mild cognitive impairment on the tip-of-the-tongue phenomenon in people naming task. Dementia and Neurocognitive Disorders. 2015;14(1):39-47. https://doi.org/10.12779 /dnd.2015.14.1.39.

136. Papenberg G, Salami A, Persson J, Lindenberger U, Bäckman L. Genetics and functional imaging: effects of APOE, BDNF, COMT, and KIBRA in aging. Neuropsychol Rev. 2015;25(1):47-62. https://doi. org/10.1007/s11065-015-9279-8.

137. Park DC, Lautenschlager G, Hedden T, Davidson NS, Smith AD, Smith PK. Models of visuospatial and verbal memory across the adult life span. Psychol Aging. 2002;17(2):299-320.

138. Park DC, Reuter-Lorenz P. The adaptive brain: aging and neurocognitive scaffolding. Annu Rev Psychol. 2009;60(1):173-96. https://doi.org/10.1146/annurev. psych.59.103006.093656.

139. Persson J, Rieckmann A, Kalpouzos G, Fischer H, Bäckman L. Influences of a DRD2 polymorphism on updating of long-term memory representations and caudate BOLD activity: magnification in aging: neurocognitive effects of a DRD2 polymorphism in aging. Hum Brain Mapp. 2015;36(4):1325-34. https://doi.org/10.1002 /hbm.22704.

140. Piccirilli M, Pigliautile M, Arcelli P, Baratta I, Ferretti S. Improvement in cognitive performance and mood in healthy older adults: a multimodal approach. Eur J Ageing. 2019;16(3):327-36. https://doi.org/10.1007 /s10433-019-00503-3.

141. Planton S, Démonet J-F. Neurophysiologie du langage: Apports de la neuro-imagerie et état des connaissances. Rev Neuropsychol. 2012;4(4):255-66. https://doi. org/10.3917/rne.044.0255.

142. Pool LR, Weuve J, Wilson RS, Bültmann U, Evans DA, Mendes de Leon CF. Occupational cognitive requirements and late-life cognitive aging. Neurology. 2016;86(15):138692. https://doi.org/10.1212/WNL.0000000000002569.

143. Raichle ME, MacLeod AM, Snyder AZ, Powers WJ, Gusnard DA, Shulman GL. A default mode of brain function. Proc Natl Acad Sci. 2001;98(2):676-82. https://doi. org/10.1073/pnas.98.2.676.

144. Ramscar M, Hendrix P, Shaoul C, Milin P, Baayen H. The myth of cognitive decline: non-linear dynamics of lifelong learning. Top Cogn Sci. 2014;6(1):5-42. https://doi. org/10.1111/tops.12078.

145. Reas ET, Laughlin GA, Bergstrom J, Kritz-Silverstein D, McEvoy LK. Physical activity and trajectories of cognitive change in community-dwelling older adults: the Rancho
Bernardo Study. J Alzheimers Dis. 2019;71(1):109-18. https://doi.org/10.3233/JAD-190491.

146. Reuter-Lorenz PA, Park DC. Human neuroscience and the aging mind: a new look at old problems. J Gerontol Ser B Psychol Sci Soc Sci. 2010;65B(4):405-15. https://doi. org/10.1093/geronb/gbq035.

147. Reuter-Lorenz PA, Park DC. How does it STAC up? Revisiting the scaffolding theory of aging and cognition. Neuropsychol Rev. 2014;24(3):355-70. https://doi. org/10.1007/s11065-014-9270-9.

148. Richards M, Deary IJ. A life course approach to cognitive reserve: a model for cognitive aging and development? Ann Neurol. 2005;58(4):617-22. https://doi.org/10.1002 /ana.20637.

149. Rossi E, Diaz M. How aging and bilingualism influence language processing: theoretical and neural models. Linguistic Approaches to Bilingualism. 2016;6(1):9-42. https://doi.org/10.1075/lab.14029.ros.

150. Roldán-Tapia MD, Cánovas R, León I, García-Garcia J. Cognitive vulnerability in aging may be modulated by education and reserve in healthy people. Frontiers in Aging Neuroscience. 2017;9:Article 340. https://doi. org/10.3389/fnagi.2017.00340

151. Rouillard M, Audiffren M, Albinet C, Ali Bahri M, Garraux G, Collette F. Contribution of four lifelong factors of cognitive reserve on late cognition in normal aging and Parkinson's disease. J Clin Exp Neuropsychol. 2017;39(2): 142-62. https://doi.org/10.1080/13803395.2016.1207755.

152. Rowe JW, Kahn RL. Human aging: usual and successful. Science. 1987;237(4811):143-9. https://doi.org/10.1126 /science.3299702.

153. Rowe JW, Kahn RL. Successful aging. The Gerontologist. 1997;37(4):433-40. https://doi.org/10.1093 /geront/37.4.433.

154. Sala-Llonch R, Bartrés-Faz D, Junqué C. Reorganization of brain networks in aging: a review of functional connectivity studies. Front Psychol. 2015;6:663. https://doi.org/10.3389 /fpsyg.2015.00663.

155. Salthouse TA. The processing-speed theory of adult age differences in cognition. Psychol Rev. 1996;103(3):40328. https://doi.org/10.1037/0033-295X.103.3.403.

156. Salthouse TA. Aging and measures of processing speed. Biol Psychol. 2000;54(1-3):35-54. https://doi.org/10.1016 /S0301-0511(00)00052-1.

157. Salthouse TA. Interrelations of aging, knowledge, and cognitive performance. In: Staudinger UM, Lindenberger U, editors. Understanding human development: dialogues with lifespan psychology: Springer US; 2003. p. 265-87. https://doi.org/10.1007/978-1-4615-0357-6_12.

158. Salthouse, T. A., \& Meinz, E. J. (1995). Aging, inhibition, working memory, and speed. J Gerontol Ser B Psychol Sci Soc Sci, 50B(6), P297-P306. https://doi.org/10.1093 /geronb/50B.6.P297

159. Satz P. Brain reserve capacity on symptom onset after brain injury: a formulation and review of evidence for threshold theory. Neuropsychology. 1993;7(3):273-95. https://doi. org/10.1037/0894-4105.7.3.273.

160. Sauter J, Widmer E, Ihle A, Kliegel M. The association of leisure activities in middle adulthood with cognitive performance in old age: social capital mediates cognitive 
reserve effects. Psychol Neurosci. 2019;12(2):236-46. https://doi.org/10.1037/pne0000146.

161. Scarmeas N, Stern Y. Cognitive reserve and lifestyle. J Clin Exp Neuropsychol. 2003;25(5):625-33. https://doi. org/10.1076/jcen.25.5.625.14576.

162. Schneider BA, Daneman M, Pichora-Fuller MK. Listening in aging adults: from discourse comprehension to psychoacoustics. Can J Exp Psychol. 2002;56(3):139-52. https://doi.org/10.1037/h0087392.

163. Sholl J, Rattan SI. Explaining health across the sciences. Springer International Publishing; 2020.

164. Schuck NW, Doeller CF, Schjeide B-MM, Schröder J, Frensch PA, Bertram L, et al. Aging and KIBRA/WWC1 genotype affect spatial memory processes in a virtual navigation task. Hippocampus. 2013;23(10):919-30. https://doi.org/10.1002/hipo.22148.

165. Schuhmann T, Schiller NO, Goebel R, Sack AT. Speaking of which: dissecting the neurocognitive network of language production in picture naming. Cereb Cortex. 2012;22(3):701-9. https://doi.org/10.1093/cercor/bhr155.

166. Shadden BB. Language and communication changes with aging. In: Shadden BB, Toner MA, editors. Aging and Communication: For Clinicians by Clinicians: PRO-Ed; 1997. p. 135-70.

167. Shafto MA, James LE, Abrams L, Tyler LK, Cam-CAN. Age-related increases in verbal knowledge are not associated with word finding problems in the Cam-CAN cohort: what you know won't hurt you. The Journals of Gerontology. Series B: Psychological Sciences and Social Sciences. 2017;72(1):100-6. https://doi.org/10.1093 /geronb/gbw074.

168. Shafto MA, Stamatakis EA, Tam PP, Tyler LK. Word retrieval failures in old age: the relationship between structure and function. J Cogn Neurosci. 2010;22(7):1530-40. https://doi.org/10.1162/jocn.2009.21321.

169. Shalev N, Brosnan MB, Chechlacz M. Right lateralized brain reserve offsets age-related deficits in ignoring distraction. Cerebral Cortex Communications. 2020;2020(1):113. https://doi.org/10.1093/texcom/tgaa049.

170. Sheldon S, Pichora-Fuller MK, Schneider BA. Priming and sentence context support listening to noise-vocoded speech by younger and older adults. The Journal of the Acoustical Society of America. 2008;123(1):489-99. https://doi. org/10.1121/1.2783762.

171. Shetreet E, Friedmann N. Stretched, jumped, and fell: an fMRI investigation of reflexive verbs and other intransitives. NeuroImage. 2012;60(3):1800-6. https://doi. org/10.1016/j.neuroimage.2012.01.081.

172. Shulman GL, Fiez JA, Corbetta M, Buckner RL, Miezin FM, Raichle ME, et al. Common blood flow changes across visual tasks: II. Decreases in cerebral cortex. J Cogn Neurosci. 1997;9(5):648-63.

173. Singh-Manoux A, Richards M, Marmot M. Leisure activities and cognitive function in middle age: evidence from the Whitehall II study. J Epidemiol Community Health. 2003;57(11):907-13. https://doi.org/10.1136 /jech.57.11.907.

174. Smith MA. Hippocampal vulnerability to stress and aging: possible role of neurotrophic factors. Behav Brain Res 1996;78(1):25-36. https://doi.org/10.1016/0166-4328(95 )00220-0
175. Smith JA, Kho M, Zhao W, Yu M, Mitchell C, Faul JD. Genetic effects and gene-by-education interactions on episodic memory performance and decline in an aging population. Soc Sci Med. 2018;112039. https://doi.org/10.1016 /j.socscimed.2018.11.019.

176. Smitha K, Akhil Raja K, Arun K, Rajesh P, Thomas B, Kapilamoorthy T, et al. Resting state fMRI: a review on methods in resting state connectivity analysis and resting state networks. Neuroradiol J. 2017;30(4):305-17. https://doi.org/10.1177/1971400917697342.

177. Snitz BE, Chang Y, Tudorascu DL, Lopez OL, Lopresti BJ, DeKosky ST, et al. Predicting resistance to amyloidbeta deposition and cognitive resilience in the oldest-old. Neurology. 2020;95(8):e984-94. https://doi.org/10.1212 /WNL.0000000000010239.

178. Sofi F, Valecchi D, Bacci D, Abbate R, Gensini GF, Casini A, et al. Physical activity and risk of cognitive decline: a meta-analysis of prospective studies. J Intern Med. 2011;269(1):107-17. https://doi.org/10.1111/j.13652796.2010.02281.x.

179. Sommers MS, Hale S, Myerson J, Rose N, Tye-Murray N, Spehar B. Listening comprehension across the adult lifespan. Ear Hear. 2011;32(6):775-81. https://doi. org/10.1097/AUD.0b013e3182234cf6.

180. Spreng RN, Lockrow AW, DuPre E, Setton R, Spreng KAP, Turner GR. Semanticized autobiographical memory and the default - executive coupling hypothesis of aging. Neuropsychologia. 2018;110:37-43. https://doi. org/10.1016/j.neuropsychologia.2017.06.009.

181. Spreng RN, Turner GR. Structure and function of the aging brain. In: Samanez-Larkin GR, editor. The aging brain: functional adaptation across adulthood: American Psychological Association; 2019. p. 9-43. https://doi. org/10.1037/0000143-002.

182. Stern Y. What is cognitive reserve? Theory and research application of the reserve concept. J Int Neuropsychol Soc. 2002;8(3):448-60. https://doi.org/10.1017 /S1355617702813248.

183. Stern Y. Cognitive reserve. Neuropsychologia. 2009;47(10):2015-28. https://doi.org/10.1016/j. neuropsychologia.2009.03.004.

184. Stordal E, Bosnes I, Romuld EB, Almkvist O. Successfully aging elderly (SAE): a short overview of some important aspects of successful aging. Norsk Epidemiologi. 2012;22(2). https://doi.org/10.5324/nje.v22i2.1555.

185. Strauss Hough M. Incidence of word finding deficits in normal aging. Folia Phoniatr Logop. 2007;59(1):10-9. https://doi.org/10.1159/000096546.

186. Tapia-Arancibia L, Aliaga E, Silhol M, Arancibia S. New insights into brain BDNF function in normal aging and Alzheimer disease. Brain Res Rev. 2008;59(1):201-20. https://doi.org/10.1016/j.brainresrev.2008.07.007.

187. Taylor JK, Burke DM. Asymmetric aging effects on semantic and phonological processes: naming in the pictureword interference task. Psychol Aging. 2002;17(4):66276. https://doi.org/10.1037/0882-7974.17.4.662.

188. Terband H, Maassen B, Maas E. A psycholinguistic framework for diagnosis and treatment planning of developmental speech disorders. Folia Phoniatr Logop. 2019;71(5-6): 216-27. https://doi.org/10.1159/000499426. 
189. Then FS, Luck T, Luppa M, Konig H-H, Angermeyer MC, Riedel-Heller SG. Differential effects of enriched environment at work on cognitive decline in old age. Neurology. 2015;84(21):2169-76. https://doi.org/10.1212 /WNL.0000000000001605.

190. Tough H, Siegrist J, Fekete C. Social relationships, mental health and wellbeing in physical disability: a systematic review. BMC public health. 2017;17(1):1-8.

191. Tsang H-L, Lee TMC. The effect of ageing on confrontational naming ability. Arch Clin Neuropsychol. 2003;18(1):81-9.

192. Tunbridge EM, Harrison PJ, Weinberger DR. Catechol-omethyltransferase, cognition, and psychosis: Val158Met and beyond. Biol Psychiatry. 2006;60(2):141-51. https://doi.org/10.1016/j.biopsych.2005.10.024.

193. Turner GR, Spreng RN. Executive functions and neurocognitive aging: dissociable patterns of brain activity. Neurobiology of Aging. 2012;33(4):826.e1-826.e13. https://doi.org/10.1016/j.neurobiolaging.2011.06.005.

194. Turner GR, Spreng RN. Prefrontal engagement and reduced default network suppression co-occur and are dynamically coupled in older adults: the default-executive coupling hypothesis of aging. J Cogn Neurosci. 2015;27(12):2462-76. https://doi.org/10.1162/jocn a 00869 .

195. Valente A, Laganaro M. Ageing effects on word production processes: an ERP topographic analysis. Language, Cognition and Neuroscience. 2015;30(10):1259-72. https://doi.org/10.1080/23273798.2015.1059950.

196. van der Merwe A. A theoretical framework for the characterization of pathological speech sensorimotor control. In: McNeil MR, editor. Clinical management of sensorimotor speech disorders. 2nd ed: Thieme; 2009. p. 3-18.

197. Verghese J, Lipton RB, Katz MJ, Hall CB, Derby CA, Kuslansky G, et al. Leisure activities and the risk of dementia in the elderly. N Engl J Med. 2003;348(25):250816. https://doi.org/10.1056/NEJMoa022252.

198. Verhaegen C, Poncelet M. Changes in naming and semantic abilities with aging from 50 to 90 years. J Int Neuropsychol Soc. 2013;19(2):119-26. https://doi. org/10.1017/S1355617712001178.

199. Verhaeghen P. Aging and vocabulary score: a meta-analysis. Psychol Aging. 2003;18(2):332-9. https://doi. org/10.1037/0882-7974.18.2.332.

200. Villar F. Successful ageing and development: the contribution of generativity in older age. Ageing Soc. 2012;32(7): 1087-105. https://doi.org/10.1017/S0144686X11000973.
201. Wang H-X, Jin Y, Hendrie HC, Liang C, Yang L, Cheng $\mathrm{Y}$, et al. Late life leisure activities and risk of cognitive decline. J Gerontol Ser A Biol Med Sci. 2013;68(2):20513. https://doi.org/10.1093/gerona/gls153.

202. Wang L, Li Y, Metzak P, He Y, Woodward TS. Agerelated changes in topological patterns of large-scale brain functional networks during memory encoding and recognition. NeuroImage. 2010;50(3):862-72. https://doi. org/10.1016/j.neuroimage.2010.01.044.

203. White KK, Abrams L. Does priming specific syllables during tip-of-the-tongue states facilitate word retrieval in older adults? Psychol Aging. 2002;17(2):226-35. https://doi.org/10.1037/0882-7974.17.2.226.

204. Wierenga CE, Benjamin M, Gopinath K, Perlstein WM, Leonard CM, Rothi LJG, et al. Age-related changes in word retrieval: role of bilateral frontal and subcortical networks. Neurobiol Aging. 2008;29(3):436-51. https://doi.org/10.1016/j.neurobiolaging.2006.10.024.

205. Wig GS. Segregated systems of human brain networks. Trends Cogn Sci. 2017;21(12):981-96. https://doi. org/10.1016/j.tics.2017.09.006.

206. Wirth M, Jann K, Dierks T, Federspiel A, Wiest R, Horn H. Semantic memory involvement in the default mode network: a functional neuroimaging study using independent component analysis. NeuroImage. 2011;54(4):3057-66. https://doi.org/10.1016/j.neuroimage.2010.10.039.

207. Wlotko EW, Lee C-L, Federmeier KD. Language of the aging brain: event-related potential studies of comprehension in older adults. Lang Ling Compass. 2010;4(8):62338. https://doi.org/10.1111/j.1749-818X.2010.00224.X.

208. Zeng Y, Cheng L, Zhao L, Tan Q, Feng Q, Chen H, et al. Interactions between social/behavioral factors and ADRB2 genotypes may be associated with health at advanced ages in China. BMC Geriatr. 2013;13(1):91. https://doi. org/10.1186/1471-2318-13-91.

209. Zhang H-Y, Chen W-X, Jiao Y, Xu Y, Zhang X-R, Wu J$\mathrm{T}$. Selective vulnerability related to aging in large-scale resting brain networks. PLoS ONE. 2014;9(10):e108807. https://doi.org/10.1371/journal.pone.0108807.

Publisher's note Springer Nature remains neutral with regard to jurisdictional claims in published maps and institutional affiliations. 